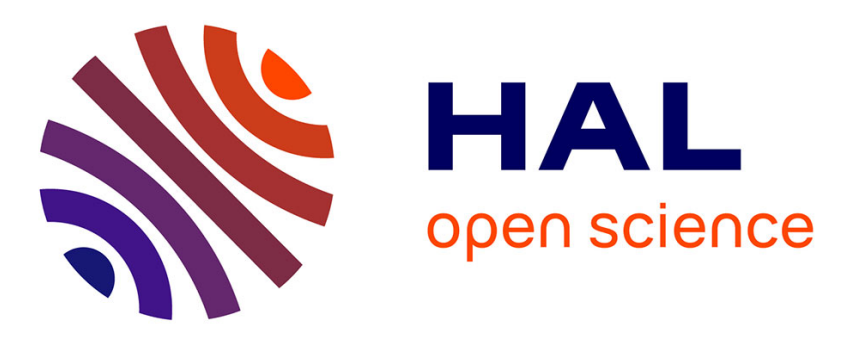

\title{
Characterization of cardiac pacemaker activity in the primate lemur Microcebus murinus
}

Mattia Difrancesco, Romain Davaze, Eleonora Torre, Pietro Mesirca, Manon Marrot, Corinne Lautier, Pascaline Fontes, Joël Cuoq, Anne Fernandez, Fabien Pifferi, et al.

\section{To cite this version:}

Mattia Difrancesco, Romain Davaze, Eleonora Torre, Pietro Mesirca, Manon Marrot, et al.. Characterization of cardiac pacemaker activity in the primate lemur Microcebus murinus. 2021. hal-03441011

\author{
HAL Id: hal-03441011 \\ https://hal.science/hal-03441011
}

Preprint submitted on 22 Nov 2021

HAL is a multi-disciplinary open access archive for the deposit and dissemination of scientific research documents, whether they are published or not. The documents may come from teaching and research institutions in France or abroad, or from public or private research centers.
L'archive ouverte pluridisciplinaire HAL, est destinée au dépôt et à la diffusion de documents scientifiques de niveau recherche, publiés ou non, émanant des établissements d'enseignement et de recherche français ou étrangers, des laboratoires publics ou privés. 
Characterization of cardiac pacemaker activity in the primate lemur Microcebus murinus.

Mattia L. DiFrancesco ${ }^{1,2,4-5}$, Romain Davaze ${ }^{3}$, Eleonora Torre ${ }^{1,2}$, Pietro Mesirca ${ }^{1,2}$, Manon Marrot ${ }^{1,2}$, Corinne Lautier ${ }^{6}$, Pascaline Fontes ${ }^{6}$, Joël Cuoq ${ }^{6}$, Anne Fernandez ${ }^{3}$, Fabien Pifferi ${ }^{7}$, Nadine MestreFrancés ${ }^{6,8}$, Matteo E. Mangoni ${ }^{1,2}$ and Angelo G. Torrente ${ }^{1,2}$.

${ }^{1}$ Institute of Functional Genomics, Univ. Montpellier, CNRS, INSERM, Montpellier, F-34095, France. ${ }^{2}$ LabEx Ion Channels Science and Therapeutics (ICST).

${ }^{3}$ Cell Biology group, Institute of Human Genetics, CNRS and Univ. Montpellier, Montpellier, F-34095, France.

${ }^{4}$ Center for Synaptic Neuroscience, Istituto Italiano di Tecnologia, Largo Rosanna Benzi 10, 16132

Genova, Italy.

${ }^{5}$ IRCCS Ospedale Policlinico San Martino, Genova, Italy.

${ }^{6}$ MMDN Univ. Montpellier, Montpellier, F-34095, France.

${ }^{7}$ UMR CNRS/MNHN 7179, Mécanismes Adaptatifs et Evolution, Brunoy, France

${ }^{8}$ EPHE, PSL Research University, Paris, France

Corresponding authors:

Dr. Matteo E. Mangoni and Angelo G. Torrente

Institute of Functional Genomics, Department of Physiology

CNRS UMR 5203, Inserm U 1191, University of Montpellier

34097 Montpellier, France

tel. +33 (0)434359246

e-mail: matteo.mangoni@igf.cnrs.fr and angelo.torrente@igf.cnrs.fr 


\begin{abstract}
Mouse lemur (Microcebus murinus) is one of the smallest and more ancestral primates known so far. It is an emerging model of senescence and neurodegeneration, thanks to its genetic proximity to humans compared to rodents. Thus, $M$. murinus could help to better understand cardiac physiology in humans. Nevertheless, the cardiac physiology of M. murinus is still unknown.

We had the opportunity to characterize cardiac activity in mouse lemurs, focusing on the pacemaker activity generation by the Sinoatrial node (SAN). Notably, we recorded cardiac activity in animals, isolated hearts, cardiac tissues and SAN pacemaker myocytes. We showed that the heart rate (HR) of mouse lemurs lays in between that of mice and rats, the rodents of closer size with M. murinus. Conversely, the ventricular depolarization of this lemur is more similar to humans or large mammals rather than small rodents.

In the SAN myocytes of $M$. murinus we recorded three of the main ionic currents involved in the SAN pacemaker activity of vertebrates, $I_{f}, I_{C a, L}$ and $I_{C a, T}$, and the expression of the SAN marker HCN4.

In parallel, we characterize skeletal muscle-derived stem cells (MDSCs) from M. murinus. These MDSCs differentiate in vitro in automatic cells showing a pacemaker-like (PML) phenotype. These cells show common features with native SAN myocytes and could be useful to test pharmacological strategies to modulate pacemaker activity.

In conclusion, the characterization of $M$. murinus HR and SAN pacemaker activity, together with the generation of PML cells pave the way for comparative studies of cardiac physiology in primates and pharmacologic tests to handle disease of cardiac automaticity.
\end{abstract}




\section{Introduction}

Situated at the venous inflow of the right atrium, the sinoatrial node (SAN) is the natural pacemaker of the heart ${ }^{1,2}$. This tissue is enriched in spindle shape cells that depolarize spontaneously to generate the cardiac impulse ${ }^{3}$. We had the chance to realize a pilot study of cardiac pacemaker activity on the small mouse lemur Microcebus murinus. To our knowledge, this is the first detailed characterization of cardiac pacemaker activity in primates. Given the closer genetic heritage with our species $^{4,5}$, this type of studies could help translate results from fundamental cardiac research to clinical approaches to treat patients affected by impaired pacemaker activity of the SAN.

The impairment of SAN pacemaker activity causes the so-called SAN dysfunctions (SNDs), which are strongly related to ageing ${ }^{6}$ and determine $\sim 500 \mathrm{k}$ implantations of electronic pacemakers in Europe ${ }^{7}$, at a cost of $\sim 2$ Billion $\$$ per year ${ }^{8}$. Given the constant increase of aged people in modern societies, SNDs are emerging as a family of diseases that urgently need therapies alternative to the classical implantation of electronic pacemakers ${ }^{9}{ }^{10}$.

With the long-term objective to find SNDs treatments alternative to the pacemaker implantation, several studies investigated the fundamental mechanism of SAN pacemaker activity ${ }^{11}{ }^{12}{ }^{13}$. Given the difficulty to access living samples of SAN from humans or closer mammals, most of the investigation on SAN activity has been pursued in rodents. In particular, with the arrival of transgenic mice, this species prevailed and allowed to discriminate the implication of specific proteins in SAN pacemaker activity $^{3,14}$.

The ionic mechanisms underlying the generation of SAN pacemaker activity are not fully understood. However, nowadays, it is generally agreed that diastolic depolarization in SAN myocytes is generated by a functional association between ionic current conducted by plasma membrane channels like hyperpolarization-activated "funny" $\mathrm{f}-(\mathrm{HCN})$ channels, L-type and T-type $\mathrm{Ca}^{2+}$ channels, and the mechanism of $\mathrm{Na}^{+} / \mathrm{Ca}^{2+}$ exchange $(\mathrm{NCX})^{15}$. While considerable evidence on the role of these currents has been collected mainly in rodents, their relative contributions to diastolic depolarization in humans is still debated because of the reduced results on SAN cells from patients ${ }^{16}$. Indeed, although SAN pacemaker activity in mice reproduces quite well the equivalent human physiology ${ }^{17}{ }^{18}{ }^{12}$, the genetic distance must be taken into consideration.

This justifies the exploration of new species, genetically closer to humans, to study cardiac pacemaker activity. Primates would be the best choice, but evident ethical concerns make that only a few studies have been conducted with this taxonomic order ${ }^{19} 2021$.

Microcebus murinus (M. murinus) is a very small and ancestral primate that can leave 4 to 5 years in nature, but can reach 12 years in captivity, undergoing a prolonged period of ageing like patients. In captivity, it is bred because, differently from rodents, it spontaneously develops age-related neurodegenerative diseases similar to humans 223242526 . Moreover, it presents unique and ancestral features for primates, like the ability to enter into a torpor state to save energies when the outside temperature drops ${ }^{27} 28$.

Common genetic origins with our species ${ }^{4,5}$ and adequate growing and reproduction rates, make mouse lemurs an excellent animal model also for cardiovascular research with translation regards towards human physiology. Nevertheless, no published data are available in cardiology for $M$. murinus.

To fulfill this gap of knowledge, we characterized cardiac pacemaker activity of mouse lemurs i) in freely moving and anesthetized animals, ii) in the isolated heart and on atrial tissue preparations, and iii) in single SAN pacemaker myocytes. In addition, we used biopsies of skeletal muscle to isolate skeletal muscle-derived stem cells (MDSCs) that differentiated in vitro into automatic cells showing a pacemaker-like (PML) phenotype with features similar to native pacemaker myocytes of the $\mathrm{SAN}^{29,30}$. 
In mammals, the frequency of heart contractions must sustain the physiological and metabolic needs, which largely depend upon the body size of the animals ${ }^{31}{ }^{32}$. The combination of the intrinsic frequency of the heart, set by the aforementioned depolarizing mechanism within the SAN, plus the modulation mediated by the autonomic nervous system, determined the resting heart rate (HR) of animals ${ }^{33,34}$. Given that mouse lemurs have an average weight of 60-80 g and a body length of $12-14 \mathrm{~cm}^{35}$, we compared our findings on $M$. murinus with previous results in mammals of similar sizes, such as rats and mice. When possible and relevant, we also compared cardiac activity in M. murinus and humans.

Going from HR quantification to the recording of ionic currents and the differentiation of PML cells, we paved the way for future cardiovascular studies on small primates and to an easier translation of results from fundamental research to clinical applications. 


\section{Results}

\section{Heart Rate (HR) recording of Mouse lemur.}

We equipped mouse lemurs of 1 to 5 years of age with telemetric transmitters to record electrocardiograms (ECGs). ECG signals allowed to discern P waves, QRS complex and T waves (Fig. 1A). Differently from small rodents, $T$ waves were well visible and in general separated from the QRS complexes by short isoelectric ST segments (Fig. $1 \mathrm{~A}$ ), as in large mammals ${ }^{36}$ and humans ${ }^{37}{ }^{38}$. Following up ECG recordings in one animal for $22 \mathrm{~h}$ we detected the main range of HR between 200 and 500 bpm (Fig. 1B), which is consistent with the body size of $M$. murinus and overlap the average HR reported for the rodents of closer size, mice and rats, respectively ${ }^{37}{ }^{39}$. Nevertheless, a gradual slowdown of HR to less than $200 \mathrm{bpm}$ was also recorded repeatedly followed by a fast HR increase (Fig. 1C, D and E). Analysing HR variability (HRV) for every interval of 5 minutes, we revealed that the dynamics of HR decrease were considerably slow (Fig. $1 \mathrm{C}$ and D). Indeed, they impacted more the index of long-term HRV, coefficient of variability of the RR interval, rather than the root mean square of successive differences between RR intervals (RMSSD), a short-term index of HRV (Fig 1D). We obtained similar results analysing long- and short-term indexes of HRV derived from Poincaré analysis (SD2 and SD1, respectively; Suppl. Fig. 1).

Further recording of HR in M. murinus under manipulation showed an average rate of $590 \pm 30 \mathrm{bpm}$ ( $n=3$, Suppl. Fig. 2), thus higher than the HR range obtained from long recordings.

We repeated ECG recording in anesthetized $M$. murinus (Fig $2 \mathrm{~A}$ and $\mathrm{B}$ ), which allows to record cardiac activity in the absence of the autonomic modulation of HR. For these experiments, we lay down the animals on a heating metal plate with temperature constantly controlled and set to $36^{\circ} \mathrm{C}$. The average HR under these conditions was $372 \pm 27 \mathrm{bpm}(n=5)$, which according to $M$. murinus body size place again its HR between those of mice and rats $^{37}{ }^{40}$. Also, on these recordings, we highlighted clear $\mathrm{T}$ waves slightly separated from QRS complexes as in freely moving $M$. murinus.

\section{Characterization of cardiac pacemaker activity by Langendorff perfusion of the whole heart and voltage optical mapping of the atrial preparation.}

To comply with the "three $R^{\prime} s$ " of animal welfare we obtained results on isolated cardiac tissue of $M$. murinus only from animals of 7 to 11 years that have been used for other studies and that after natural ageing must be euthanized for factors, not cardiac related, which hamper normal life. Thanks to these animals, we recorded ECG signals from isolated hearts, removed under deep anaesthesia and complete loss of hind-limb reflex, indicative of cerebral death. After removal, the heart of these animals was placed on a Langendorff system, showing robust and regular frequency (Fig. $3 \mathrm{~A}$ ), with an average rate of $232 \pm 80 \mathrm{bpm}$.

On the heart isolated from others $M$. murinus, we further investigated the generation of pacemaker activity in the intact atrial preparation, after removal of ventricular chambers. Such preparation, which includes SAN, right and left atria, in $M$. murinus was about twice the size observed in mice of equivalent ages (Fig 3B). Moreover, differently from mice, the size of left atria in M. murinus was significantly larger than right atria (Supp. fig.1).

Thanks to the technique of voltage optical mapping, we recorded the rate of action potentials (APs) in the SAN region of $M$. murinus and mice (Fig $3 C$ and $D$ ). Moreover, we determined where it is generated the first electrical activity in the SAN of $M$. murinus (leading region) and how it is conducted towards the atria (Fig. 3E and Suppl. video 1). We reported an average pacemaker frequency of $236 \pm 18$ 
APs/min, which is significantly slower and about half of what we measured in mice (Fig $3 \mathrm{C}$ and $\mathrm{D}$ ), but faster than what has been recorded in rats ${ }^{39}$.

We also tested the sensitivity of isolated hearts to positive and negative modulation with the natural agonistes of the $\beta$-adrenergic and vagal modulation. When $\beta$-adrenergic agonist epinephrine (Epi; 30 $\mathrm{nM}$ ) was perfused in the Langendorff system or on the atrial preparations analysed by optical mapping, we observed only a tendency to positive chronotropic modulation (Fig. 2A and F). Conversely, when the vagal effector acetylcholine (Ach; $50 \mathrm{nM}$ ) was perfused in the Langendorff system or on the atrial preparations, we observed a significant rate reduction (Fig. 2F). In the atrial preparation, the modulations of SAN rate by Epi and Ach was associated with delocalization of the leading regions toward the frontal or caudal portion of the SAN (Fig. 3E), similarly to what we have already shown in mice ${ }^{41}$.

3. Native pacemaker myocytes isolated from the mouse lemur SAN conduct $I_{f}$ and $I_{c a}$ ionic currents and generate spontaneous APs and intracellular $\mathrm{Ca}^{2+}$ transients.

To characterize the fundamental mechanism of SAN pacemaker activity at the cellular level, we freshly isolated single pacemaker myocytes from the SAN tissue of the mouse lemur. After enzymatic digestion, we observed single pacemaker myocytes with self-contractile properties (data not shown) and spindle shapes similar to SAN myocytes of mice ${ }^{3}$, rats $^{42}$ and humans ${ }^{16}$ (Fig. 4A).

Immunostaining of single pacemaker myocytes and intact SAN tissues from $M$. murinus revealed the expression of $\mathrm{HCN} 4$ channels, which are considered one of the predominant pacemaker mechanisms of the SAN (Fig. 4B, C and D). In the pacemaker myocytes isolated from the SAN we attempted to record three of the main currents involved in the mechanism of automaticity: $I_{f}$, and the L-type and Ttype $\mathrm{Ca}^{2+}$ currents, $I_{C a, L}$ and $I_{C a, T}$, respectively (Fig. $5 \mathrm{~A}$ and B). In addition, we recorded the inwardrectifier $\mathrm{K}^{+}$current $I_{\mathrm{K} 1}$ (Fig. $5 \mathrm{~A}$ and $\mathrm{B}$ ), which has been reported also in the SAN of mice ${ }^{43}$ and rats ${ }^{42}$.

When cell capacitance was considered, the current densities of $I_{k 1}$ and $l_{f}$ were similar to that recorded in rat SAN myocytes ${ }^{42}$. Current density of $I_{f}$ appeared very similar also to mice ${ }^{44}$, thus about 2.5 higher than human ${ }^{16}$. In comparison to mouse, SAN myocytes from M. murinus, showed reduced total $\mathrm{Ca}^{2+}$ current ( $\left.I_{C a, T o t:} I_{C a, L}+I_{C a, T}\right)$, possibly due to lower $I_{C a, T}$. However, the density of $I_{C a, L}$ appeared similar to that in SAN myocytes from mice ${ }^{45}$, with a similar threshold of activation, but a more positive peak of current density at $0 \mathrm{mV}$, as shown in rats ${ }^{42}$.

In SAN cells of M. murinus superfused with Tyrode's control solution, patch-clamp recordings of pacemaker activity showed an average rate of $148 \pm 22 \mathrm{APs} / \mathrm{min}$ ( $n=7$; Fig. 6A). Moreover, under the same control condition, in these myocytes we record spontaneous generation of intracellular $\mathrm{Ca}^{2+}$ transients at a rate of $82 \pm 23$ per $\min$ ( $n=11$ Fig. 6B).

We then tested the possibility to modulate the pacemaker activity of $M$. murinus SAN myocytes with the agonists of the $\beta$-adrenergic and muscarinic receptors, Epi and ACh, respectively (Fig. 6B). Analysing SAN cells recorded by patch-clamp or line scan, we found only a tendency to rate increase after Epi stimulation (Fig. 6B and C). Conversely, Ach superfusion in the same type of SAN myocytes, significantly reduced the rate of APs and intracellular $\mathrm{Ca}^{2+}$ transients (Fig. $6 \mathrm{~B}$ and $\mathrm{C}$ ). In addition, the specific $I_{f}$ blocker ivabradine $(1 \mu \mathrm{M})$ significantly decreased the rate of intracellular $\mathrm{Ca}^{2+}$ transients, while the blocker of ryanodine receptor (RyR), ryanodine (Ry) tended to decrease the rate of intracellular $\mathrm{Ca}^{2+}$ transients (Fig. 6B and D). 


\section{Automatic cells (Pacemaker-Like; PML) differentiated from MDSC share similar feature with native SAN pacemaker cells.}

Although small primates like $M$. murinus are easier to keep in captivity, their availability remains limited and will be always much reduced than classical rodent models, like mice and rats. On the other hand, in vitro preparations of stem cells are increasingly used to understand cell physiology and the function of ion channels ${ }^{46}$. Therefore, to have an in vitro system to easily test pharmacological approaches in cardiac cells from primates, we used skeletal muscle biopsies of $M$. murinus and we attempted to differentiate cells that replicate some of the characteristics of SAN pacemaker myocytes. Initially, these MDSCs consisted of heterogeneous pluripotent stem cells. Taking advantage of the preplating technique to isolate $\mathrm{MDSCs}^{29}$, we were able to isolate a subpopulation of cells that present some of the typical features of native pacemaker myocytes of the SAN. For that, we cultured MDSCs in vitro for 66 to 74 days, to ensure a full differentiation towards the sustained beating phenotype of PML cells ${ }^{30}$.

Similar to the phenotype of SAN pacemaker myocytes, PML cells expressed HCN4 and L-type Cav1.3 channels as well as Connexine 45 (Fig. 7A), which are all typical markers of native SAN pacemaker myocytes in mice ${ }^{3}$. Moreover, like native pacemaker myocytes isolated from the $M$. murinus SAN, PML cells showed spontaneous contractions that could be measured by the coordinated movement of their edges. This allowed to record the rate of the spontaneous activity in these cultured cells with no need for enzymatic digestion or reagent incubation. In this way, we left PML cells in a physiological condition convenient for a dose-response analysis of modulators compounds.

Taking advantage of this technique, we measured the spontaneous contraction rate in PML cells under control conditions and after superfusion with increasing doses of Epi, Ach, ivabradine and E4031. Under control conditions, PML cells showed spontaneous contractility at a rate of $171 \pm 13$ cell beats/min ( $n=33 ;$ Fig. 7B), a rate comparable to AP firing measured in native SAN pacemaker from $M$. murinus (see above). After exposure to modulator compounds in the extracellular medium, PML cells responded accordingly with the expression of functional $\mathrm{f}$-channels, $\mathrm{I}_{\mathrm{kr}}$ and membrane receptors typical of native pacemaker myocytes, with a significant and reproducible acceleration or deceleration that was proportional to the concentration of the drug tested (Fig 7B and C). Indeed, both the $I_{f}$ current blocker ivabradine and the $I_{k r}$ inhibitor E-4031 decreased the rate of spontaneous contractions of PML cells, in agreement with functional expression of HCN4 and ERG channels.

Spontaneously active PML cells revealed the ability to generate automatic AP firing with a rate of 161 $\pm 14 \mathrm{APs} / \mathrm{min}$ ( $\mathrm{n}=12$; Fig. 7D), which is comparable with what we recorded in native cardiac pacemaker myocytes of $M$. murinus (see above). The larger availability of cells prepared in vitro, in comparison with native myocytes, allowed for a wider pharmacological screening of drugs known to modulate cardiac pacemaker activity at the cellular level. Indeed, we tested $\beta$-adrenergic and muscarinic modulation by superfusing the natural agonists Epi and Ach. In addition, we tested the functional presence of cardiac sodium channels by superfusing the specific blocker tetrodotoxin.

Similarly, to what was described for native cardiac pacemaker myocytes, the firing rate of PML cells showed an increase of $87 \pm 25 \%$ in APs/min under $\beta$-adrenergic stimulation with Epi (30nM), while Ach $(50 \mathrm{~nm})$ and tetrodotoxin reduced the spontaneous rate of PML cells by $49 \pm 11 \%$ and $41 \pm 13 \%$, respectively (Fig 7D and E). 


\section{Discussion}

M. murinus, also known as the mouse lemur is an arboreal and nocturnal primate among the smallest and more ancestral of its order ${ }^{47}$. This primate is an emerging animal model to study neurodegenerative diseases related to ageing and given its genetic proximity to humans it could also help study cardiac physiology ${ }^{47}$. In addition, its small size and relatively easy reproduction make affordable its breeding in captivity, maintaining a viable population that could be reintroduced in the wild to preserve this species and fight against the threatening of habitat loss.

Impaired autonomic modulation of the heart is part of the causes of abnormal cardiac activity in aged patients. Differently from rodents, $M$. murinus presents spontaneous age-related neurodegeneration similarly to humans ${ }^{23}$, which could likely affect also the regulation of cardiovascular system function by the autonomic nervous system. Thus $M$. murinus could better recapitulate a neural environment similar to humans, to study cardiac pacemaker activity and age-related SNDs.

Despite these advantages, so far, there are no studies that investigated the cardiac physiology of $M$. murinus. To fill this gap of knowledge, we applied a range of techniques to characterize the HR and pacemaker activity of $M$. murinus. When possible, we compared our findings on $M$. murinus with previous data published in rodents of similar size (mice and rats), as well as with humans.

These comparisons showed that freely moving or anesthetized $M$. murinus have a range of HR that overlap the average HR in mice and rats ${ }^{39}{ }^{40}$, which is consistent with the small size of this primate.

On the other hand, $M$. murinus presents cardiac features that distinguish these animals from small rodents. In particular, the ECGs of mouse lemurs present T waves clearly separated from the QRS complex, which suggests a dynamic of repolarization more similar to large mamals ${ }^{36}$ and humans ${ }^{37}{ }^{38}$, rather than to small rodents. In addition, we observed recurrent and slow decreases of HR to frequency as low as $120 \mathrm{bpm}$ that were often followed by sudden HR increase. We do not have an immediate explanation for this HR decrease, but its prolonged dynamic suggests that it could be a physiological phenomenon more complex than the classical HR reduction by the fast activation of vagal modulation ${ }^{34}$. We hypothesize that this slow HR decrease could be part of the mechanism that allows $M$. murinus to enter into a torpor state to save energy when the outside temperature drops ${ }^{27}$ 28 .

Analysis of the size of atrial preparations in $M$. murinus showed that it is about twice those of mice. In accordance with a bigger size, the APs frequency of the intact SAN tissue in $M$. murinus was significantly slower than the equivalent preparation in mice. Moreover, the larger left versus right atria could be due to left atria enlargement to compensate for the deficiency of left ventricles contraction as observed in aged patient ${ }^{48}$. Similarly, to the intact SAN tissue, in single pacemaker myocytes of $M$. murinus we found that the spontaneous rate of APs and intracellular $\mathrm{Ca}^{2+}$ transients were in between those recorded in SAN myocytes of mice and rats ${ }^{2,36}$.

Our investigation of the ionic currents underlying pacemaker activity demonstrated the presence of three among the main currents involved in the generation of spontaneous APs, $I_{f}, I_{C a, L}$ and $I_{C a, T}$, respectively. We also report here the expression of the pacemaker marker HCN4 in single myocytes and the intact SAN tissue of $M$. murinus. Expression of HCN4 and $I_{f}$, together with $I_{C a, T}$ and the lowvoltage activated $I_{C a, L}$, likely encoded by L-type $\mathrm{Ca}_{\mathrm{v}} 1.3$ channels, suggest the implication of those currents in the generation of M. murinus pacemaker activity, similarly to what is known for mice 3245 .

In addition, and similar to what was previously reported in SAN myocytes from mice ${ }^{43}$ and rats $^{42}$, we also recorded $\mathrm{Ba}^{2+}$ sensitive $I_{k 1}$ at densities comparable to that observed in rat SAN myocytes ${ }^{42}$. This 
current is almost absent in SAN myocytes of larger mammals, while it is conducted at a higher density in the working myocardium and in Purkinje fibers, where it is responsible for negative diastolic potential versus SAN myocytes ${ }^{3}$. Nevertheless, the presence of this current in mice ${ }^{43}$, rats $^{42}$ and $M$. murinus suggests that it could be specific to SAN myocytes of small mammals.

Concerning the classical modulation of the heart by the autonomic nervous system, we found a positive chronotropic response when recording HR under manipulation. On the other hand, $\beta$ adrenergic stimulation with Epi in tissue or single cells only showed a tendency of rate increase. Conversely, activation of the muscarinic pathway by Ach superfusion significantly reduced the rate of all the preparations tested. We also observed that the automaticity of pacemaker myocytes from the M. murinus SAN was negatively regulated by the $I_{f}$ blocker Ivabradine. Moreover, Ry in the $\mu$ molar range, which locks the intracellular $\mathrm{Ca}^{2+}$ release channel, tended to slow down the generation of intracellular $\mathrm{Ca}^{2+}$ transients. The slowing of pacemaker activity to $I_{f}$ blockers and ryanodine has been consistently observed in SAN myocytes from all mammalian models used so far and is integrated in currently accepted models of pacemaker activity ${ }^{49,50}$.

Finally, we obtained MDSCs from skeletal muscle biopsies. From MDSCs we isolated PML cells using a technique that has been previously demonstrated to differentiate automatic cells that share similar features with native pacemaker myocytes of the $\mathrm{SAN}^{29,30}$. In our recordings, these PML cells showed spontaneous contractile activity and generation of APs at a rate comparable to native pacemaker myocytes of $M$. murinus. Moreover, PML cells expressed the classical markers of native pacemaker myocytes, notably $\mathrm{HCN} 4, \mathrm{Ca}_{\mathrm{v}} 1.3$ and $\mathrm{Cx} 45$, and presented with positive and negative $\beta$-adrenergic and muscarinic chronotropic effects on automaticity.

A further investigation is ongoing ${ }^{30}$ to better understand the degree of similarity between PML cells and native SAN myocytes of $M$. murinus. Nevertheless, our results indicate that cultured PML cells share common features with native pacemaker myocytes. Thus, they could represent a valid model for preliminary investigation of the effects of pharmacological compounds on the mechanism of cardiac pacemaking in primates.

In conclusion, we provided the first characterization of the cardiac pacemaker activity of $M$. murinus to propose this primate as a valuable animal model to investigate age-related SND with a neurodegenerative context similar to humans. Moreover, in the future, this initial characterization will help understand the mechanism behind the state of torpor of these lemurs. While the ability to enter a state of torpor could appear anecdotic at first, it could have important applications to induce artificial coma, to avoid organ failure, and for the slowdown of human metabolism during long-term space flight $^{28}$.

Thus, our general characterization of $M$. murinus HR and pacemaker activity opens the way to an easier translation of cardiac results in primates to human physiology. Moreover, it put the basis for future investigation of the cardiac physiology allowing the state of torpor in M. murinus, which could bring to develop medical applications to slow-down human metabolism.

\section{Methods}

\section{Care and use of animals.}

The investigation conforms to the Guide for the Care and Use of Laboratory Animals published by the US national Institute of Health (NIH Publication No. 85-23, revised 1996) and European directives (2010/63/EU). Males and females of M. murinus, from 1 to 11 years of age were used. Specifically, animals from 1 to 5 years were used for telemetry experiment with minimal invasive or external device 
of ECG recording. These animals were reintegrated to the colony after the experimentation. Conversely, animals from 7 to 11 years that after natural ageing must be euthanized for factors hampering normal life and not cardiac related were used for all the other experiments. This approach avoided extra increase of the colony in the respect of the "three R's" of animal welfare: replacement, reduction, and refinement.

Mouse lemurs used for implantation and ECG recording were hosted at the mouse lemur colony of Brunoy (MECADEV, MNHN/CNRS, IBISA Platform, agreement F 91.114.1, DDPP, Essonne, France) and their use was conducted under the approval of the Cuvier Ethical Committee (Committee number 68 of the "Comité National de Réflexion Ethique sur l'Expérimentation Animale"), under authorization number 68-018. In the respect of the principle of "three R's" of animal welfare, the use of these data, collected during another project for other purpose, allowed reduction of animal use since we did not have to implant new animals for the present project. All the other Mouse lemurs came from the colony housed at RAM-CECEMA (license approval 34-05-026-FS, DDPP, Hérault, France). Their use was conducted under the approval of the CEEA-LR Ethical Committee (Committee number 36). Animals were euthanized at the end of their lives and all organs were collected immediately for biomedical research.

\section{Housing conditions}

All animals were housed in cages equipped with wood branches for climbing activities as well as wooden sleeping boxes mimicking the natural sleeping sites of mouse lemurs. The temperature and the humidity of the rooms were maintained at $25-27^{\circ} \mathrm{C}$ and at $55-65 \%$, respectively. In captivity, the artificial daily light-dark cycles within the housing rooms are changed to mimic season alternation, with periods of 6 months of summer-like long days ( $14 \mathrm{~h}$ of light and $10 \mathrm{~h}$ of darkness, denoted 14:10) and 6 months of winter-like short days (10 h of light and $14 \mathrm{~h}$ of darkness, denoted 10:14). Animals were fed ad libitum (with fresh fruits, warms and a homemade mixture) ${ }^{51}$.

\section{ECG recordings.}

One-lead surface ECGs were recorded from freely moving and anesthetized mouse lemurs. For ECG recording in freely moving animal implanted with a transmitter. Surgeries were conducted in sterile conditions, under veterinarian supervision. After administration of diazepam (Valium, $1 \mathrm{mg} / 100 \mathrm{~g}$, i.m.) and buprenorphine $(0.005 \mathrm{mg} / 100 \mathrm{~g}$, i.m.), anesthesia was induced and maintained by $1-3 \%$ isoflurane inhalation. Body temperature was maintained with a heating mat, and the animal's eyes were protected with ocular gel (Ocry-gel; Laboratoire TVM, Lempdes, France). A small transmitter (PhysioTel F20-EET, 3.9 g, 1.9 cc; Data Sciences International, DSI, St. Paul, United States) connected with 1 pair of electrode wires (silicon elastomer insulated stainless-steel wires, diameter: $0.3 \mathrm{~mm}$ ) was inserted inside the peritoneal cavity of the animal. Electrode wires were led subcutaneously from the abdomen to the thorax muscle and were sutured using non-absorbable polyamide monofilament suture thread. similarly to the procedure applied in mice ${ }^{40}$. After surgery, nociception was minimized by subcutaneous injection of analgesic and anti-inflammatory drugs (meloxicam, $0.2 \mathrm{mg} / 100 \mathrm{~g}$ ). ECG signals were recorded using a telemetry receiver and an analog-to-digital conversion data acquisition system (Data Sciences International). HR and HRV data were analyzed with the dedicated software Labchart 8 (ADInstruments, Dunedin, New Zealand).

For external ECG, we use custom-made gel electrodes and soft surgical tape to place on the back of mouse lemurs the Xiaomi Youpin HiPee Intelligent Dynamic Holter produced by Zhejiang Helowin Medical Technology Co., Ltd (Hangzhou, China). Before that, the animals were first shaved in the contact points with the gel electrodes to facilitate the conduction of the signal through the skin. ECG 
signals were recorded through three electrodes positioned in raw that allowed to obtain one lead with the ground. ECGs recordings were obtained through a specific application software provided by the Helowin company. ECGs obtained 10 to $15 \mathrm{~min}$ after the application of the Holter device were used for the HR analysis under manipulation.

For ECG recordings under anesthesia, we constantly exposed mouse lemurs to $1.5 \%$ of isofluorane. Body temperature of mouse lemurs was continuously maintained at $36^{\circ}-37^{\circ} \mathrm{C}$ using a heated pad connected to a controller that received feedback from a temperature sensor attached to the animal. $\mathrm{Ag} / \mathrm{AgCl}$ gel-coated ECG electrodes (Unomedical; Herlev, Danimarca) were attached to the superior right and to the two inferior limbs of the mice lemur. The electrodes were connected to a standard one-lead ECG amplifier module (EMKA Technologies, Paris, France), which included high- and low-pass filters (set to $0.05 \mathrm{~Hz}$ and $500 \mathrm{~Hz}$, respectively) and a gain selection device (set to 1,000-fold). Signals were digitized continuously at $2 \mathrm{kHz}$ and recorded using an IOX data acquisition system (EMKA Technologies, France). The recordings were carried out for a 45-minute period, and the software ECGAuto (EMKA Technologies, France) was used to perform offline analysis of the data recorded. For each mouse lemur the mean HR, its Standard Deviation and the parameters characterizing the ECG wave, were calculated on 30-min intervals taken $10 \mathrm{~min}$ after the beginning of each 45 -min recording.

\section{Langendorff perfused hearts.}

After general anesthesia, consisting of $0.1 \mathrm{mg} / \mathrm{g}$ of Ketamine (Imalgène, Merial, Bourgelat France) and complete loss of hind-limb reflex, indicative of cerebral death, we removed the heart from the thoracic cage of mouse lemurs and quickly mounted it on a Langendorff apparatus (Isolated heart system; EMKA Technologies) at a constant pressure of $80 \mathrm{~mm} \mathrm{Hg}$ with normal Tyrode's solution. Perfused hearts were immersed in the water-jacked bath and maintained at $36^{\circ} \mathrm{C}$. ECGs were continuously recorded by $\mathrm{Ag}-\mathrm{AgCl}$ electrodes positioned on the epicardial side of the right atrium close to the SAN area and near the apex. The HR was allowed to stabilize for at least 30 min before perfusion of Epi 30 $\mathrm{nM}$ or Ach $50 \mathrm{nM}$.

\section{Preparation of atrial preparation and optical voltage mapping.}

Atrial preparations (including SAN, right and left atria) were obtained as described previously ${ }^{52}$. Briefly, as described in the previous paragraph, after general anaesthesia with Ketamine (Imalgène, Merial, Bourgelat France) and complete loss of hind-limb reflex, we removed the heart from the thoracic cage of the animal. Then, we cut the coronary sinus and starting from it, we removed the ventricles from the heart. We used a stereomicroscope (SZX16, Olympus; Tokyo, Japan) with low magnification (7X) to trans-illuminate and visualize directly the remaining atrial preparation constituted by the SAN plus right and left atria. We identified the SAN region using the borders of the superior and inferior vena cava, the crista terminalis and the interatrial septum as landmarks ${ }^{18}$. The atrial preparation was pinned to the bottom of an optical chamber (Fluorodish, FD35PDL-100, WPI; Sarasota, FL) coated with $\sim 2 \mathrm{~mm}$ of clear Sylgard (Sylgard 184 Silicone elastomer kit; Dow Corning; Midland, MI). To avoid interference from secondary pacemaker tissues we removed the atrio-ventricular node from the preparation.

For comparative experiments, mice of 24 months were used to match the age of $M$. murinus used to obtain tissue preparation of the SAN. As for M. murinus the investigation with mice conforms to the European directives (2010/63/EU) for the Care and Use of Laboratory Animals and was approved by the French Ministry of Agriculture ( $\mathrm{N}^{\circ} \mathrm{D} 34-172-13$ ). Briefly, mice were anesthetized with $0.01 \mathrm{mg} / \mathrm{g}$ of Xylazine (Rompun 2\%, Bayer AG, Leverkusen Germany), $0.1 \mathrm{mg} / \mathrm{g}$ of Ketamine (Imalgène, Merial, Bourgelat France) and $0.2 \mathrm{mg} / \mathrm{g}$ of Na-Pentobarbital (CEVA, France). Then, after complete loss of hind- 
limb reflex, we removed the heart from the thoracic cage of the animal and we dissected it to obtain the entire atrial preparation (SAN, right and left atria) ${ }^{52}$

To analyse voltage changes in the atrial preparation we loaded it by immersing the tissue in a Tyrode's solution containing the voltage-sensitive indicator Di-4-ANEPPS $(2 \mu \mathrm{mol} / \mathrm{L})$. This immersion was done at room temperature $\left(20-22^{\circ} \mathrm{C}\right)$ and last for at least $30 \mathrm{~min}$. To maintain proper oxygenation, the chamber containing the tissue was maintained under agitation for the whole loading period. After the loading step, the tissue was washed in dye-free Tyrode for $15 \mathrm{~min}$. During this step, the temperature was slowly increased to $34-36^{\circ} \mathrm{C}$. The atrial preparation was then constantly superfused at $34-36^{\circ} \mathrm{C}$ and imaged by high-speed optical voltage mapping (1000 to $333 \mathrm{frames} / \mathrm{s}$ ) on a MiCAM03 Camera $256 \times 256$ pixel CMOS sensor, $17.6 \times 17.6$ mm (SciMedia; Costa Mesa, CA). This camera was mounted on a THT Microscope, with two objectives ( $2 \mathrm{X}$ and 1.6X) that generated a field of view of $22 \times 22 \mathrm{~mm}$. A system constituted by a $150 \mathrm{~W}$ halogen light and a built-in shutter (SciMedia; Costa Mesa, CA) was used as the excitation source of light for the voltage dye. The filter set included a 531/50 nm excitation filter, $580 \mathrm{~nm}$ dichroic mirror, and 580 long-pass emission filter. To avoid motion artifacts, we blocked mechanical activity using blebbistatin $(10 \mu \mathrm{M} \text {; Tocris Bioscience; Bristol, UK })^{52}$. Optical raw data were analysed using dedicated software from the camera developer, BV workbench (Brainvision; Tokyo, Japan), in combination with ClampFit (ver. 10.0.7, Molecular Devices, LLC; San Jose, California).

\section{Isolation of SAN myocytes.}

The SAN tissue of mouse lemur was isolated as described above and cut in tissue strips. Strips were then transferred into a low-Ca ${ }^{2+}$, low- $\mathrm{Mg}^{2+}$ solution containing (in $\mathrm{mM}$ ): $140.0 \mathrm{NaCl}, 5.4 \mathrm{KCl}, 0.5 \mathrm{MgCl} 2$, $0.2 \mathrm{CaCl} 2,1.2 \mathrm{KH} 2 \mathrm{PO} 4,50.0$ taurine, $5.5 \mathrm{~d}$-glucose, $1.0 \mathrm{mg} / \mathrm{ml} \mathrm{BSA}$, and 5.0 HEPES-NaOH (adjusted to pH 6.9 with $\mathrm{NaOH}$ ). The tissue was enzymatically digested by adding $229 \mathrm{U} / \mathrm{ml}$ collagenase type II (Worthington Biochemical Corporation), $1.9 \mathrm{U} / \mathrm{ml}$ elastase (Boehringer Mannheim), $0.9 \mathrm{U} / \mathrm{ml}$ protease (Sigma-Aldrich), $1 \mathrm{mg} / \mathrm{ml} \mathrm{BSA}$, and $200 \mu \mathrm{M} \mathrm{CaCl} 2$. Tissue digestion was performed for a variable time of 9-13 min at $35^{\circ} \mathrm{C}$ with manual agitation using a flame-forged Pasteur pipette. Tissue strips were then washed and transferred into a medium containing (in $\mathrm{mM}$ ): $70.0 \mathrm{~L}$-glutamic acid, $20.0 \mathrm{KCl}, 80.0$ $\mathrm{KOH}, 10.0$ ( \pm ) D- $\beta$-OH-butyric acid, $10.0 \mathrm{KH} 2 \mathrm{PO} 4,10.0$ taurine, $1 \mathrm{mg} / \mathrm{ml} \mathrm{BSA}$, and $10.0 \mathrm{HEPES}-\mathrm{KOH}, \mathrm{pH}$ 7.4 with $\mathrm{KOH}$. SAN myocytes were manually dissociated in $\mathrm{KB}$ solution at $35^{\circ} \mathrm{C}$ for about $10 \mathrm{~min}$. Cellular automaticity was recovered by readapting the myocytes to physiological extracellular $\mathrm{Na}^{+}$and $\mathrm{Ca}^{2+}$ concentrations by adding aliquots of solutions containing (in $\mathrm{mM}$ ): $10.0 \mathrm{NaCl}, 1.8 \mathrm{CaCl}$, and, subsequently, normal Tyrode's solution containing $1 \mathrm{mg} / \mathrm{ml} \mathrm{BSA}$. The final storage solution contained (in $\mathrm{mM}$ ): $100.0 \mathrm{NaCl}, 35.0 \mathrm{KCl}, 1.3 \mathrm{CaCl} 2,0.7 \mathrm{MgCl} 2,14.0$ I-glutamic acid, 2.0 ( \pm )D- $\beta$-OH-butyric acid, $2.0 \mathrm{KH} 2 \mathrm{PO} 4,2.0$ taurine, and $1.0 \mathrm{mg} / \mathrm{ml} \mathrm{BSA}, \mathrm{pH} 7.4$. Cells were then stored at room temperature until use. All chemicals were obtained from Sigma-Aldrich, except for the $( \pm) D-\beta$-OHbutyric acid, which was purchased from Fluka Chemika. For electrophysiological recording, SAN myocytes in the storage solution were harvested in special custom-made recording plexiglass chambers.

\section{Preparation and culturing of MDSCs and PML cells.}

MDSCs were prepared using the modified preplate procedure originally described by Arsic et al. ${ }^{29}$ and modified recently ${ }^{30}$. Briefly, after general anesthesia, consisting of $0.1 \mathrm{mg} / \mathrm{g}$ of Ketamine (Imalgène, Merial, Bourgelat France) and complete loss of hind-limb reflex indicative of cerebral death, the hind limb muscles of mouse lemurs were removed, minced and enzymatically dissociated at $37^{\circ} \mathrm{C}$ for 45 $\mathrm{min}$ in $0.2 \%$ collagenase $A$ (Roche) and $1 \mathrm{mg} / \mathrm{ml}$ dispase (GibcoBRL). After digestion, muscle cells were passed through $40 \mu \mathrm{m}$ nylon cell strainer (BD Falcon) and centrifuged at $328 \mathrm{~g}$ for $10 \mathrm{~min}$. Pelleted cells were washed twice in phosphate buffer saline (PBS), suspended in the growth medium [DMEM/F12 (Sigma), 16\% fetal bovine serum (PAA), 1\% Ultroser G (Pall Life Sciences), antibiotic- 
antimycotic mix (Gibco)] and plated on uncoated dishes (NUNC). After an initial 40 min pre-plating, non-adherent pluripotent stem cells were transferred to a new dish every $24 \mathrm{~h}$ for 4 to 6 days. For confocal microscopy experiments, cells were seeded onto glass-bottom chambers (Fluorodish, FD35PDL-100, WPI; Sarasota, FL). Otherwise, they were cultured in standard $35 \mathrm{~mm}$ petri dishes. To ensure a full maturation of spontaneously differentiated stem cells, culturing was prolonged for 1 to 3 months before experimentation, and PML cells were selected as spontaneously-contractile cells, and based on their morphology.

\section{Patch-clamp recordings of $M$. murinus SAN myocytes and PML cells.}

Myocytes isolated from the M. murinus SAN were prepared as described in the previous sections, while PML cells were enzymatically treated with brief digestion of 3 to 5 minutes at $37^{\circ} \mathrm{C}$ with 229 $\mathrm{U} / \mathrm{ml}$ collagenase type II (Worthington Biochemical Corporation), and washed in Tyrode solution for enzyme removal, leaving cells in their culture Petri-dish. The basal extracellular Tyrode's solution used in all recordings contained (in $\mathrm{mM}$ ): $140.0 \mathrm{NaCl}, 5.4 \mathrm{KCl}, 1.8 \mathrm{CaCl}, 1.0 \mathrm{MgCl} 2,5.0 \mathrm{HEPES}-\mathrm{NaOH}$, 5.5 and d-glucose (adjusted to $\mathrm{pH} 7.4$ with $\mathrm{NaOH}$ ). To measure the hyperpolarization-activated current $l_{f}$, we employed standard Tyrode's solution in the presence or absence of $2 \mathrm{mM} \mathrm{Ba}^{2+}$ to block the inward rectifier $\mathrm{K}^{+}$current $I_{k 1}$, without affecting $l_{f}^{53}$. $I_{k 1}$ was subtracted from $I_{f}$ as the net $\mathrm{Ba}^{2+}$ sensitive conductance, while $I_{f}$ was extracted as the currents not blocked under perfusion of $\mathrm{Ba}^{2+}$, but subsequently inhibited in the presence of $5 \mathrm{mM} \mathrm{Cs}^{+}$. $I_{C a, \mathrm{~L}}$ and $I_{C a, T}$ were recorded as previously described ${ }^{45}$. In particular, $I_{\text {Сато }}\left(I_{\text {CaT }}+I_{\text {CaL }}\right)$ was recorded from a holding potential of $-80 \mathrm{mV}$ in isolated SAN myocyte. Then after switching HP to $-55 \mathrm{mV}$ we inactivate $I_{\mathrm{CaT}}$ to obtain only $\mathrm{I}_{\mathrm{Ca}, \mathrm{L}}$.

AP firing activity was measured in the current clamp (CC) configuration. Patch-clamp electrodes had a resistance of 4-5 M $\Omega$ when filled with an intracellular solution containing (in $\mathrm{mM}$ ): $130.0 \mathrm{~K}^{+}-$ aspartate; $10.0 \mathrm{NaCl} ; 2.0 \mathrm{ATP}-\mathrm{Na}^{+}$salt, 6.6 creatine phosphate, $0.1 \mathrm{GTP}-\mathrm{Mg}^{2+}, 0.04 \mathrm{CaCl} 2$ (pCa = 7.0), and 10.0 Hepes $\mathrm{KOH}$ (adjusted to $\mathrm{pH} 7.2$ with $\mathrm{KOH}$ ). For the modulation of AP firing, we perfused Epi $30 \mathrm{nM}$, Ach $50 \mathrm{nM}$, and tetrodotoxin $30 \mu \mathrm{M}$. Compounds were added to the external medium and perfused through a pipette at a controlled temperature of $36^{\circ} \mathrm{C}$. Pacemaker activity of SAN and PML cells was recorded under perforated patch conditions by adding $50 \mu \mathrm{M} \beta$-escin to the pipette solution.

\section{Confocal imaging of intracellular $\mathrm{Ca}^{2+}$ fluctuations.}

Intracellular $\mathrm{Ca}^{2+}$ release was recorded in SAN pacemaker myocytes loaded with Fluo-4 AM at room temperature $\left(22-24^{\circ} \mathrm{C}\right)$. Pacemaker myocytes were distinguished from other excitable myocyte types (i.e. atrial myocytes) by their morphology (spindle, spider and elongated) and size ( $10 \mu \mathrm{m}$ diameter). Images were obtained with confocal microscopy (Meta Zeiss LSM 510 and Zeiss LSM 780), by scanning the myocyte with an Argon laser in line scan configuration (1.54 ms line rate); fluorescence was excited at $488 \mathrm{~nm}$ and emissions were collected at $>505 \mathrm{~nm}$. A 63x oil immersion objective was used to record $\mathrm{Ca}^{2+}$ release in isolated pacemaker myocytes. Images were corrected for the background fluorescence and the fluorescence values (F) were normalized to the basal fluorescence (F0) to obtain the fluorescence ratio (F/FO). Integrals of light intensity were analysed by pClamp software (ver.9, Molecular Devices) and spontaneous $\mathrm{Ca}^{2+}$ transients were analysed by ImageJ software.

\section{Measurements of cell shortening of PML cells.}

Contractions of PML cells were recorded using a video-based edge-detection system (lonOptix ${ }^{\mathrm{TM}}$ ). PML cells preparations were placed on the stage of an inverted microscope (Olympus IX71). Digitized images were collected at $120 \mathrm{~Hz}$ using an lonOptix ${ }^{\mathrm{TM}}$ Myocam-S CCD camera, and displayed within the lonWizard ${ }^{\mathrm{TM}}$ acquisition software (IonOptix ${ }^{\mathrm{TM}}$ ). To measure changes in cells length, two cursors were placed at opposite edges of the sample defined as the difference in optical density (maximum: dark; 
minimum: light) and cell shortening was assessed by the simultaneous movement of the cursors. For the modulation of contraction rate, we perfused Epi ( $1 \mathrm{nM}$ to $1 \mu \mathrm{M}$ ), ACh (1 to $50 \mathrm{nM}$ ), ivabradine ( 3 $\mathrm{nM}$ to $3 \mu \mathrm{M})$ and E4031 (300 nM and $3 \mu \mathrm{M})$. Compounds were added to the external medium and perfused through a pipette at a controlled temperature of $36^{\circ} \mathrm{C}$.

\section{Immunofluorescence analysis}

Immunofluorescence analysis was performed on SAN tissue, native SAN pacemaker myocytes and PML cells ${ }^{29}$. Tissues and cells were fixed with $3.7 \%$ formaldehyde for 30 and $5 \mathrm{~min}$, respectively. Then these samples were permeabilized for $30 \mathrm{~s}$ in $-20^{\circ} \mathrm{C}$ acetone, preincubated 30 min with $0.5 \%$ BSA in PBS. Cells were then incubated for $1 \mathrm{~h}$ at $37^{\circ} \mathrm{C}$ with primary antibodies against HCN4, (1:100, Alomone), sarcomeric alpha-actinin, clone EA-53 (1:100, Sigma-Aldrich), connexin 45 (1:100, H-85, Santa Cruz Biotechnology), $\mathrm{Ca}_{\mathrm{v}} 1.3 \mathrm{Ca}^{2+}$ channel polyclonal antibody (N38.8, neuromab UC Davis), cardiac troponin I (1:100, Millipore), caveolin 3 (1:100, BD Transduction Laboratories) and myogenine, (1:50, sc576 santa cruz). Specific staining was revealed using anti-mouse or anti-rabbit Alexa Fluor 488 and Alexa Fluor 555-conjugated secondary antibodies (InVitrogen) with Hoechst33358 nuclear stain (0,1 $\mu \mathrm{g} / \mathrm{ml}$ ) for $30 \mathrm{~min}$ at $37^{\circ} \mathrm{C}$.

\section{Statistical analysis}

Significance was evaluated through Student's T test, one-way- or two-way ANOVA as specified in figure legends. When testing statistical differences results were considered significant with $p<0.05$. Data analysis were performed with GraphPad Prism 9.0

\section{Acknowledgments}

We are thankful to the personal of the animal facility of the lemur colony at Brunoy, to the animal facility at RAM-CECEMA, the MRI platform of imaging and the statistic platform Statabio. We thank Fu Lingjian and Dr. Yuquan Wang for helping in software installation. M-L DiFrancesco was recipient of a postdoctoral fellowship by the Laboratory of Excellence Ion Channel Science and Therapeutics supported by a grant from Agence Nationale de la Recherche (ANR-11-LABX-0015). This work was supported by ANR grants (2010-BLAN-1128-01 and ANR-15-CE14-0004-01 to M.E.M.) and the Fondation Leducq (TNE FANTASY 19CVD03 to Matteo E. Mangoni and Peter J. Mohler). 
Figures:

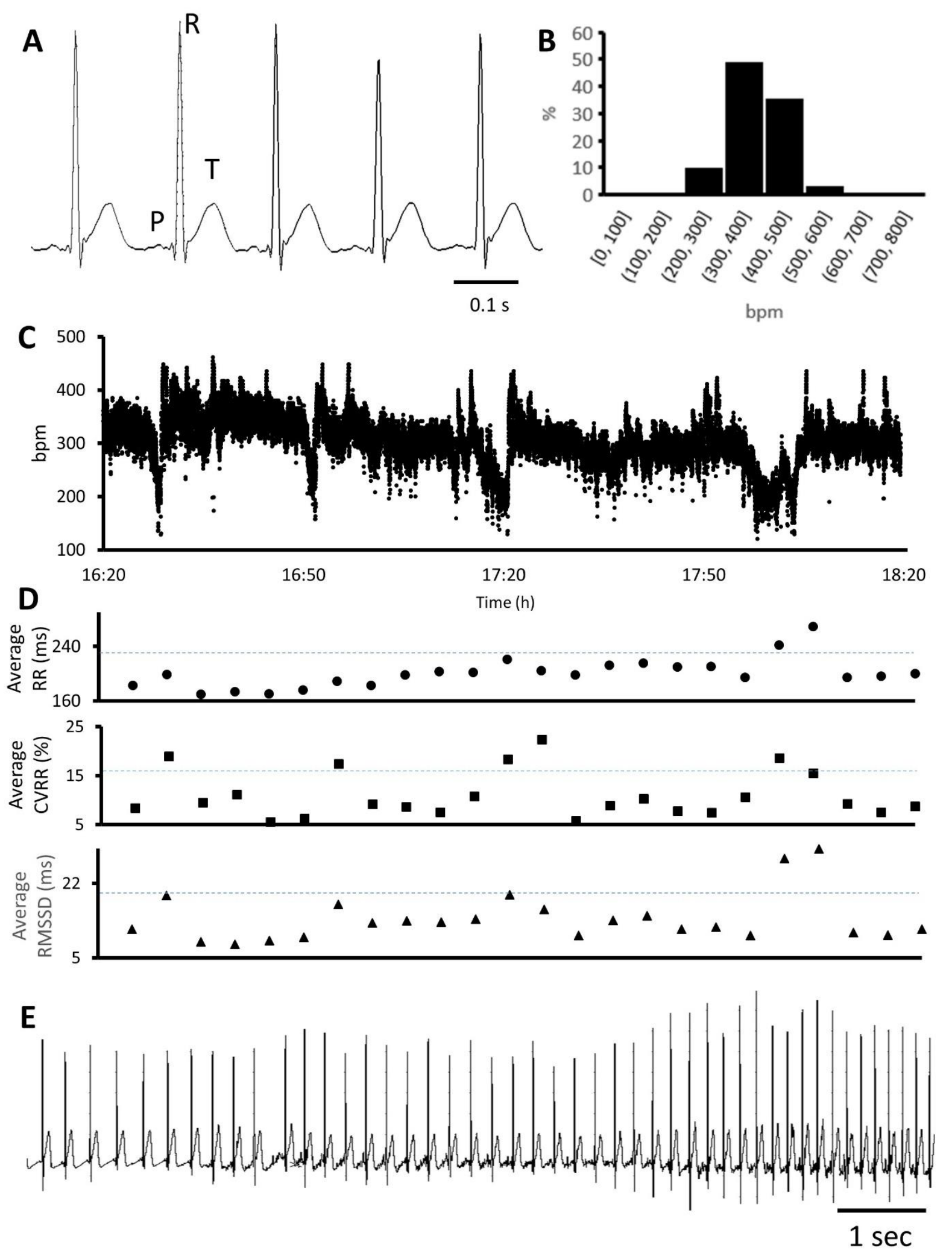

Figure 1: In vivo recording of cardiac activity in mouse lemurs.

A: Example traces of ECGs in freely moving $M$. murinus. Note $P, R$ and $T$ waves. B: Range of $H R$ measured during 22 hours of ECG recording in one animal. C: Example of 2 hours recording showing 
HR development versus time. Note the cyclical decrease of HR to very low frequencies. Data for ECG recordings in implanted $M$. Murinus were recorded in 3 animals. D: Plots obtained by averaging the RR interval, its coefficient of variability and RMSSD during consecutive intervals of 5 minutes, covering the two hours recording shown in C. Dashed blue lines indicate the threshold of mean+SD for each of the parameters reported. E: ECG recording showing very slow heartbeat followed by a strong increase of HR. Data for ECG recordings in implanted M. Murinus were recorded in 3 animals.

A

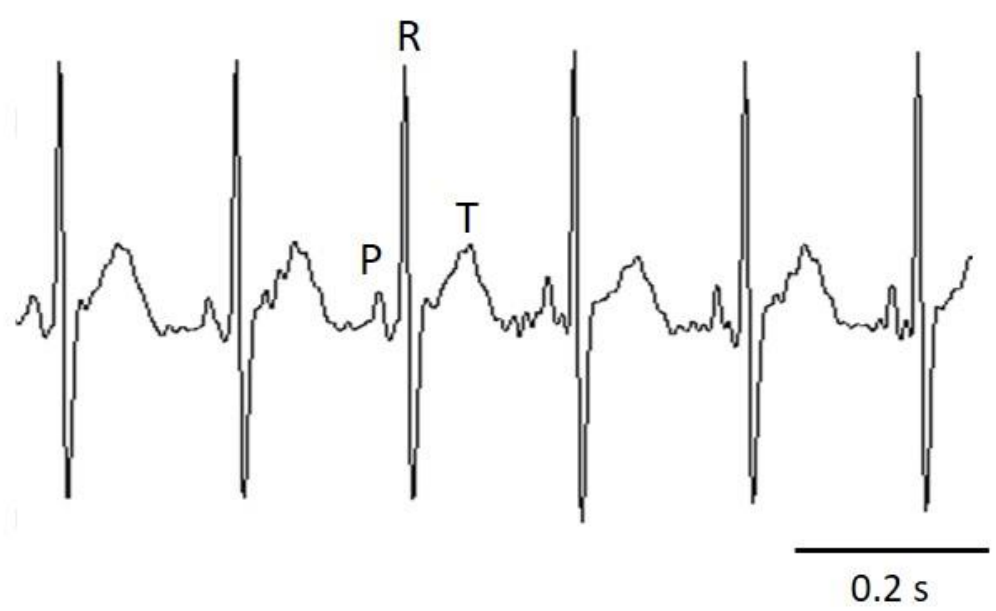

B

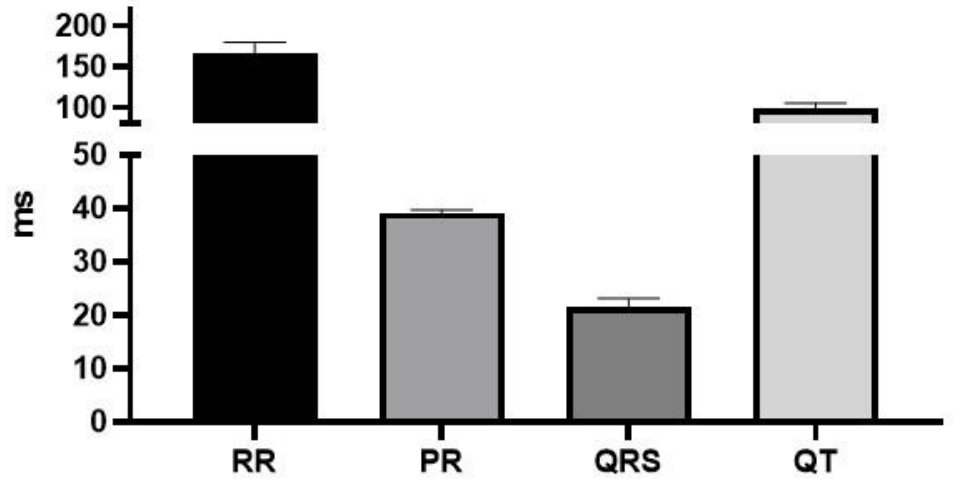

Figure 2: ECG of anaesthetized mouse lemurs.

A: ECGs from anesthetized mouse lemurs. Note P, R and T waves. B: Parameters characterizing the ECG waves of anesthetized mouse lemurs $(n=5)$. 

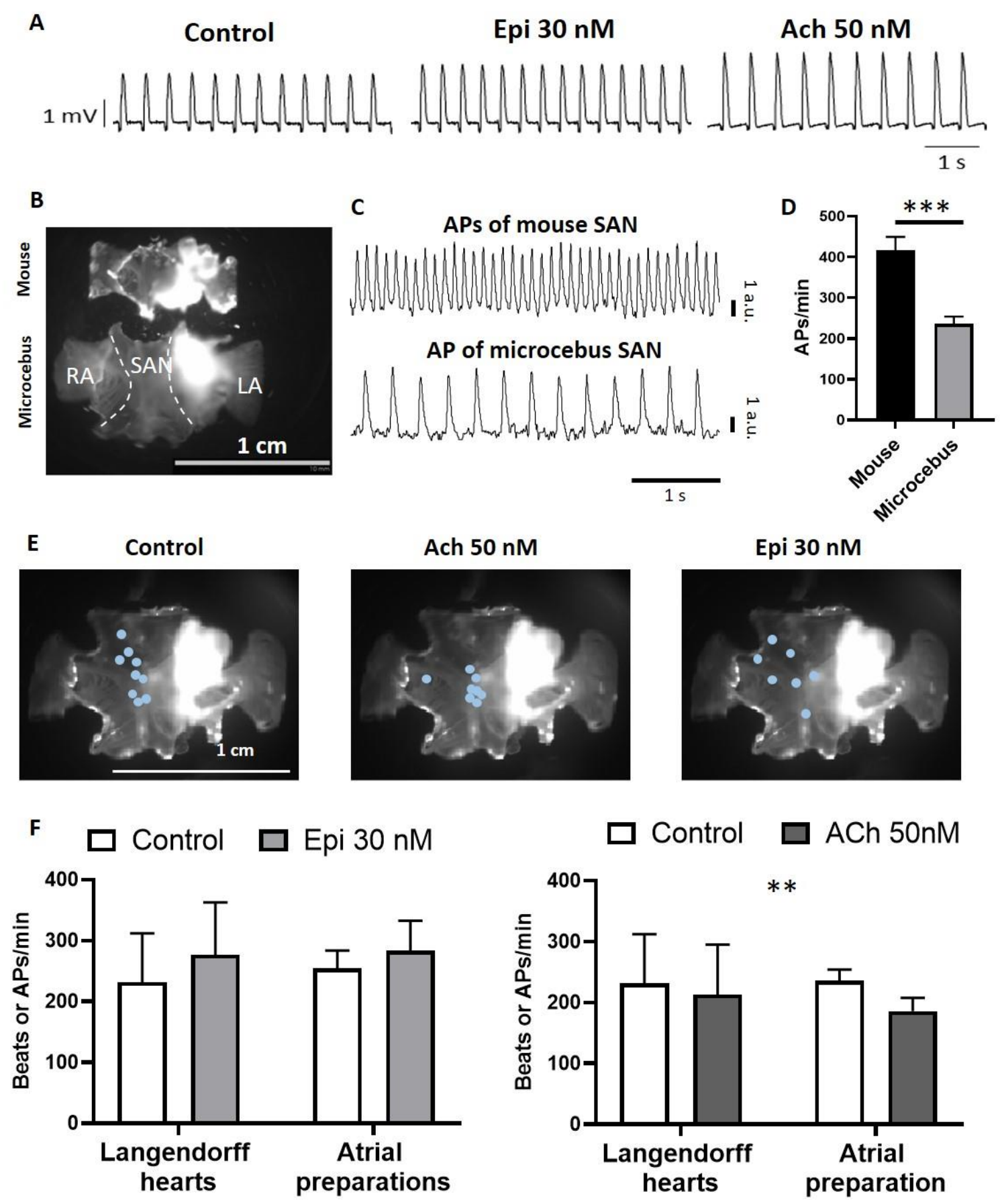

Figure 3: Automaticity of isolated hearts and atrial preparation. A: Example traces of electrical activity from isolated hearts maintained alive with a Langendorff system. Traces have been recorded under control and perfusion of Epi $(30 \mathrm{nM})$ and ACh $(50 \mathrm{nM})$. B: Examples of atrial preparations dissected in mouse and $M$. murinus, including the sinoatrial node (SAN), the right and left atria (RA and LA, respectively). C: Traces of optical APs recorded in the SAN of mouse and $M$. murinus. APs amplitude is expressed in arbitrary units. D: AP rate recorded in mouse and $M$. murinus under the control condition (Tyrode's superfusion; $n$ mouse $=13, \mathrm{n}$ Microcebus $=9$ ). E: Dots indicating the origin of pacemaker activity in the atrial preparations of $M$. murinus hearts. F: Change of bpm or AP rate after Epi or ACh superfusion, in the isolated heart $(N=3)$ or the intact $S A N(N=6$ in Epi and $N=9$ in $A C h$ ) of M. murinus. ${ }^{* *} p<0,001$ and ${ }^{* * *} p<0.001$ by unpaired T-test and two-way Anova. 
A
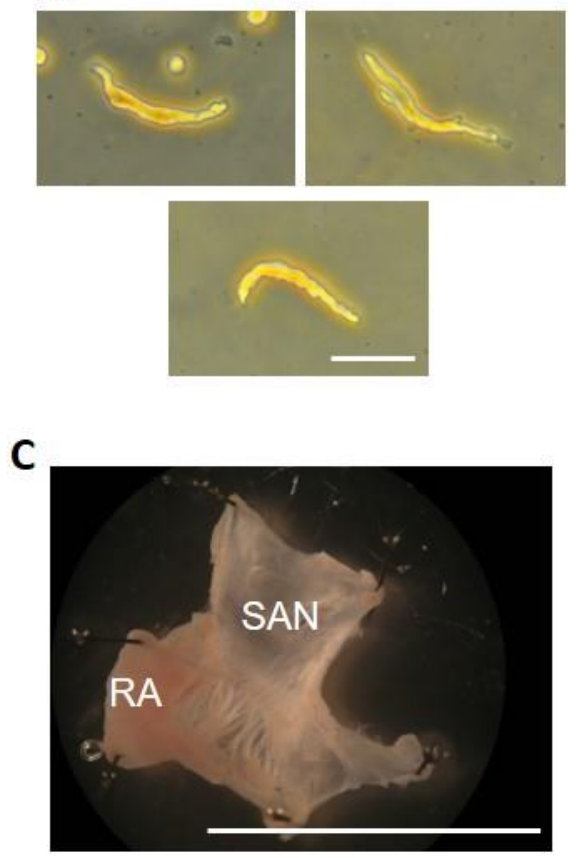

B

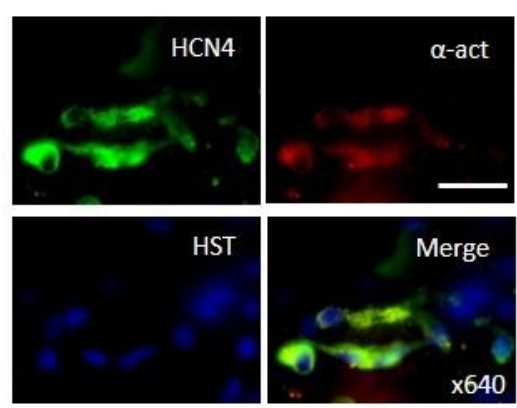

D

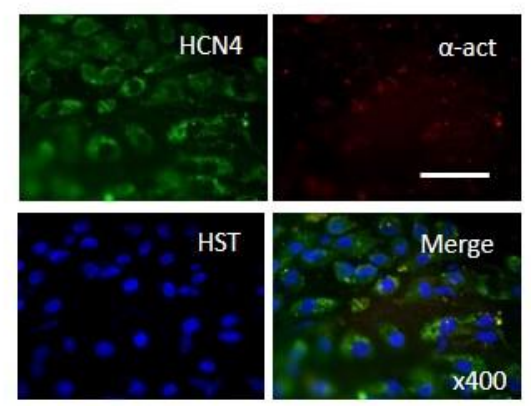

Fig 4: Immuno-detection of cardiac-pacemaker markers from mouse lemur SAN tissue and isolated myocytes.

A: Freshly isolated pacemaker myocytes obtained from the $M$. murinus SAN tissue (Bar $=50 \mu \mathrm{m})$. B) Labelling of HCN4, $\alpha$-actine, nuclei (Hoechst33358; HST) and merged picture in SAN pacemaker myocytes $(B a r=30 \mu \mathrm{m})$. C) Dissection of the Sinoatrial preparation showing the SAN and the right atrium (Bar $=10 \mathrm{~mm}$ ). D) Labelling of HCN4, $\alpha$-actine, nuclei (HST) and merged picture in the pacemaker myocytes within the intact SAN tissue $($ Bar $=40 \mu \mathrm{m})$.

A

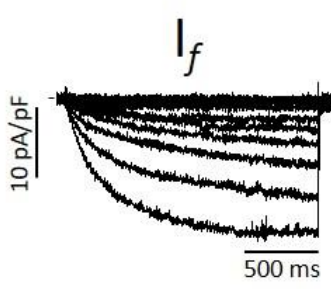

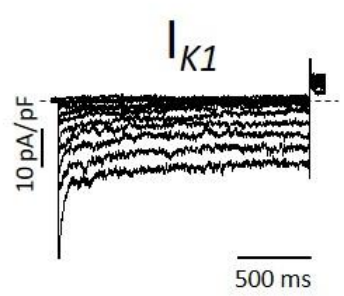
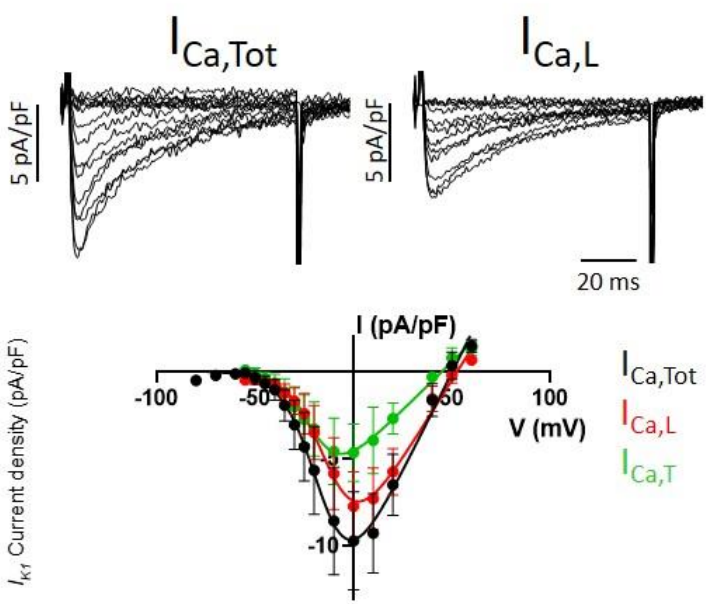

Figure 5: Recordings of ionic currents in mouse lemur SAN pacemaker myocytes.

A: Sample traces of $I_{f}, I_{K 1}, I_{C a, T o t}$ and $I_{C a, L}$ ( $\mathrm{n}=3,2$ and 4, respectively). B: Current-to-voltage relationships of densities of ionic currents described in panel $A$. 


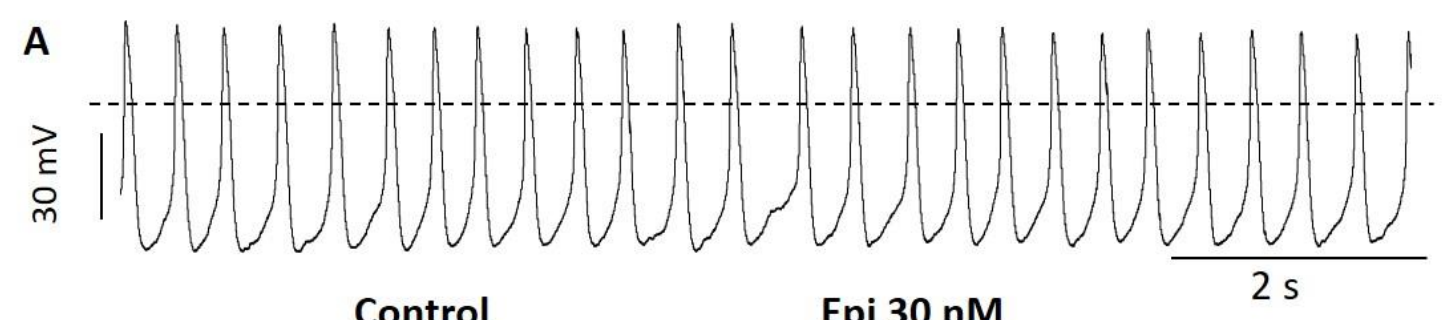

Control

Epi $30 \mathrm{nM}$

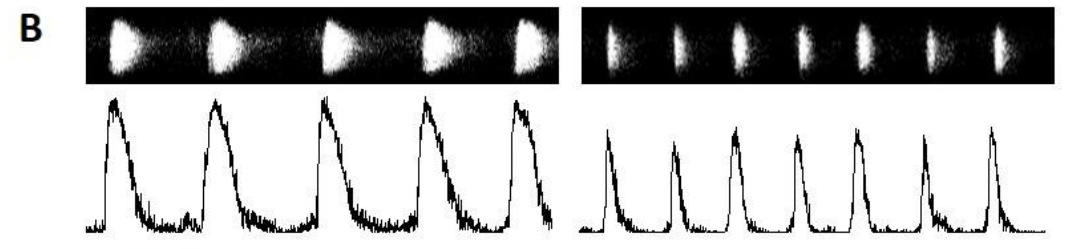

ACh $50 \mathrm{nM}$

Iva $1 \mu \mathrm{M}$
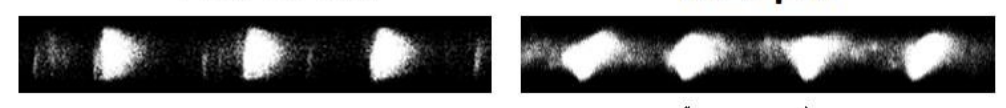

Ry $3 \mu \mathrm{M}$
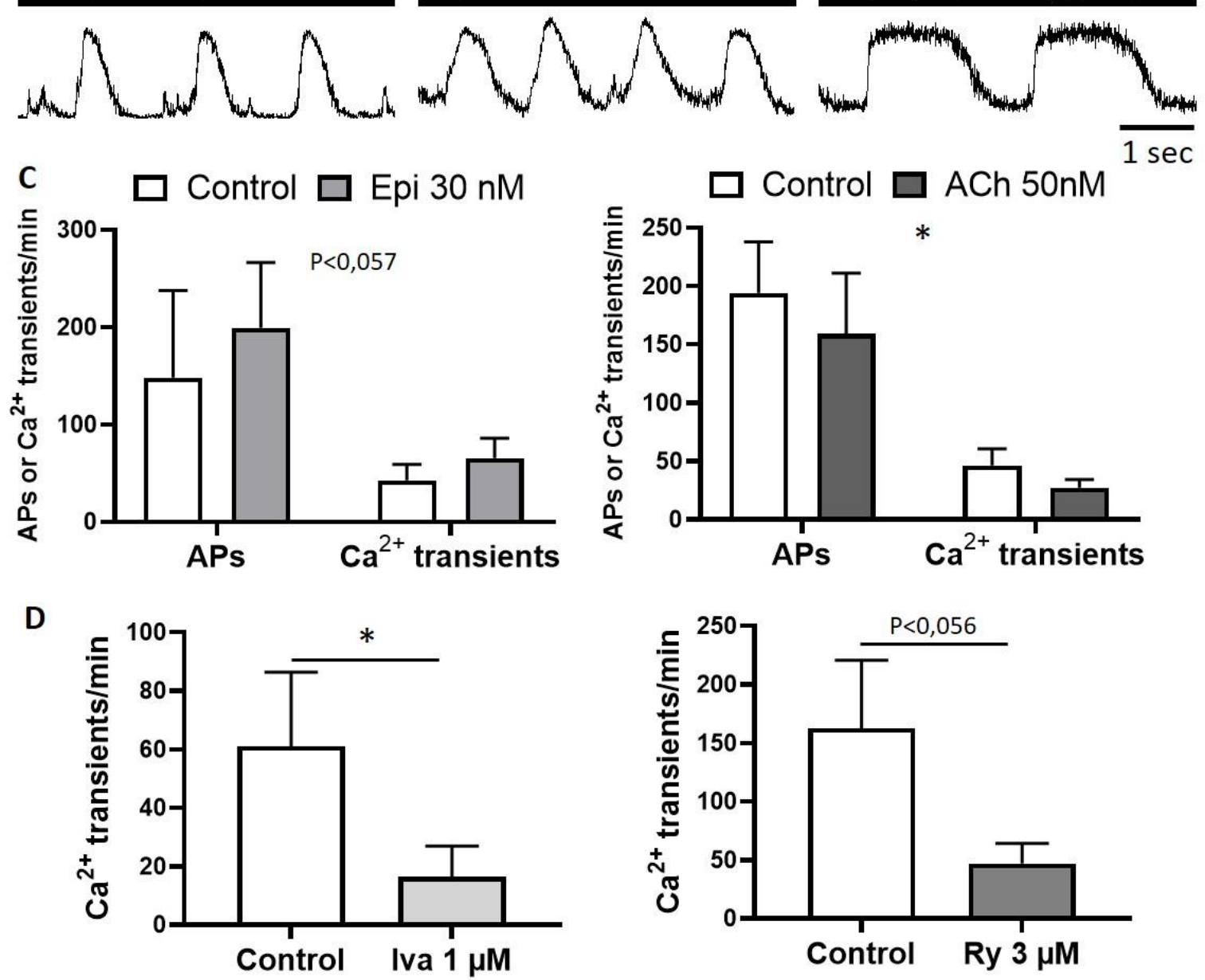

Figure 6: Patch-clamp recording of APs and confocal line-scan analysis of mouse lemur SAN pacemaker myocytes.

A: APs recorded of SAN pacemaker myocytes from M. murinus under Tyrode's superfusion. B: Spontaneous $\mathrm{Ca}^{2+}$ transients recorded in SAN pacemaker myocytes under the control condition and after perfusion of Epi, ACh, ivabradine and ryanodine. C: Effect of Epi and ACh superfusion on the rate of APs ( $n=2$ in Epi and $n=2$ in Ach) and $\mathrm{Ca}^{2+}$ transients ( $n=2$ in Epi and $n=3$ in Ach). D: Changes in the 
rate of $\mathrm{Ca}^{2+}$ transients after perfusion of the IVA $(n=4)$ and $\mathrm{Ry}(n=3) .{ }^{*} p<0.05$ by two-way Anova and paired T-test.

A

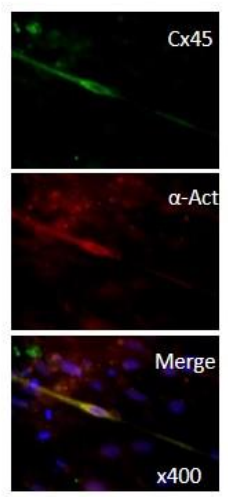

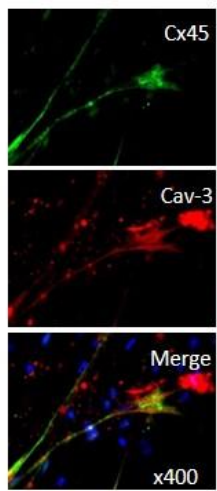
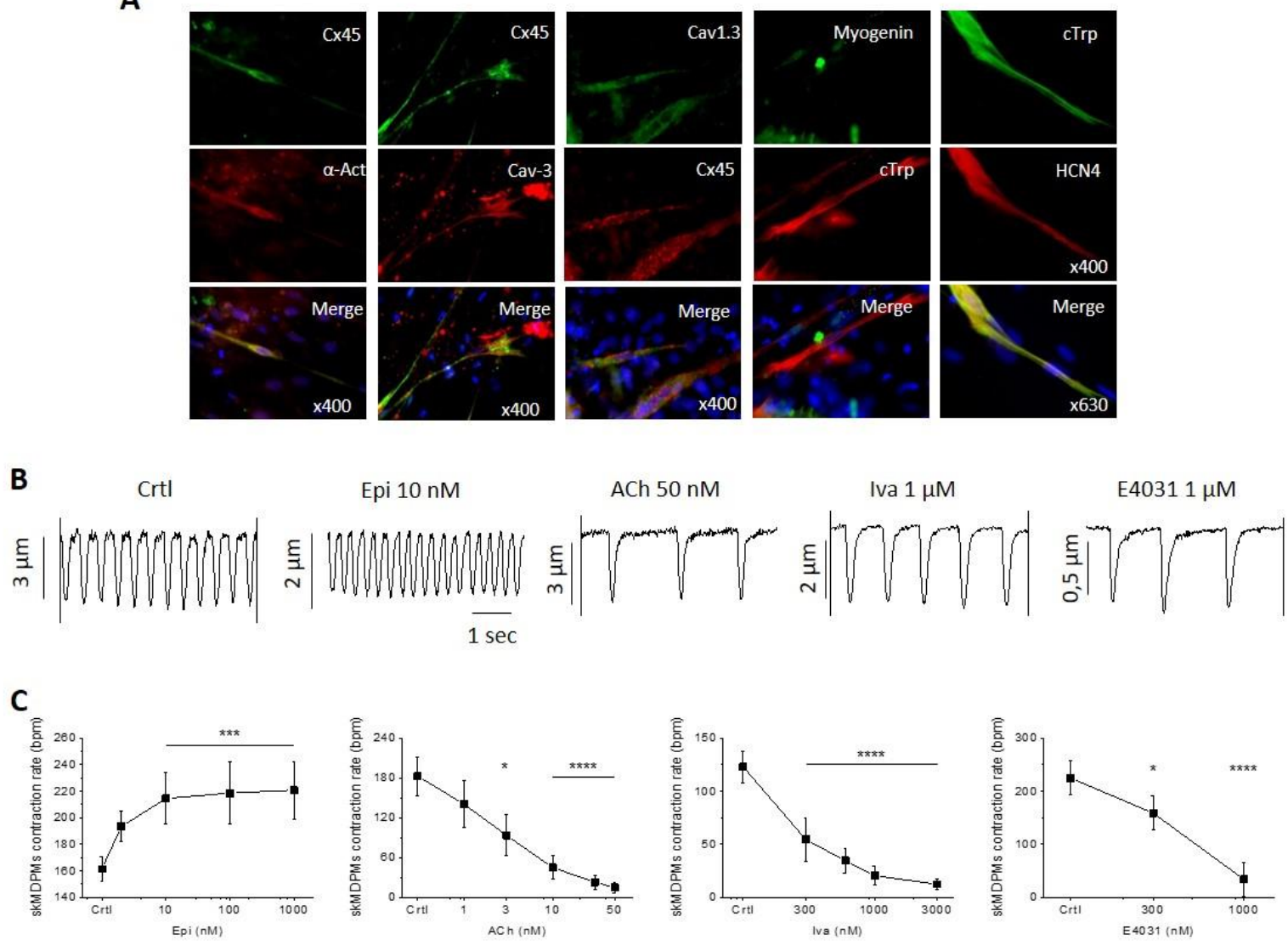

D

Ctrl

Epi $30 \mathrm{nM}$

ACh $50 \mathrm{nM}$

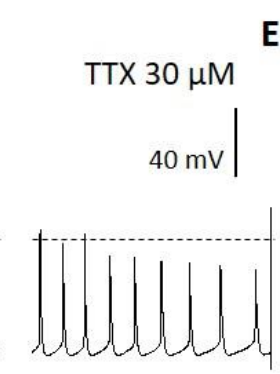

E
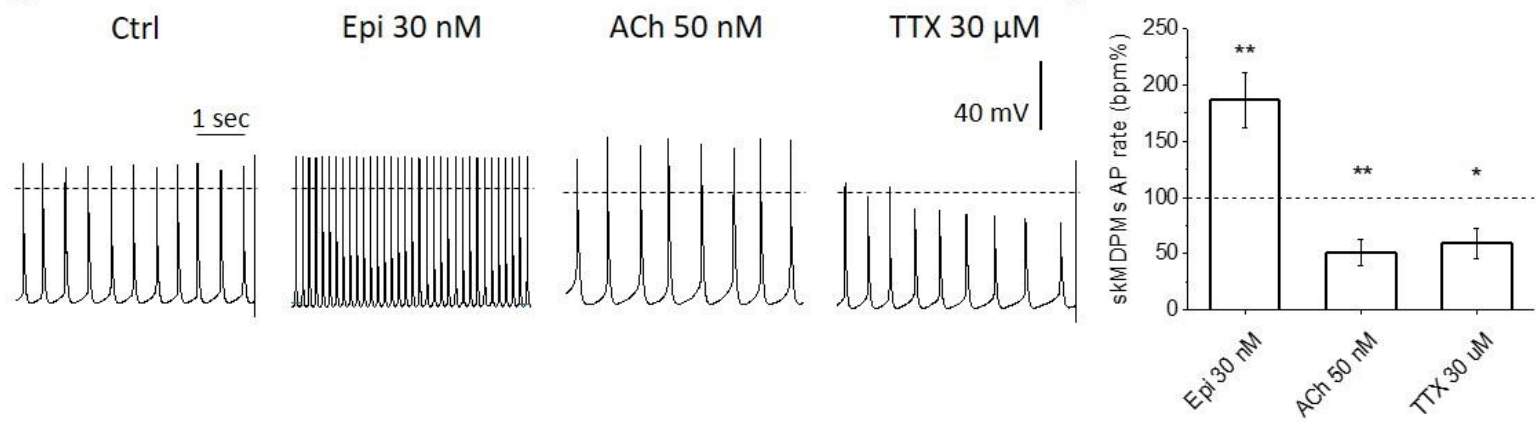

Figure 7: Properties of mouse lemur PML cells.

A: Immunostaining of PML cells with the SAN marker Cx45, Cav1,3 and HCN4 plus sarcomeric alphaactinin ( $\alpha$-Act), Caveoline 3 (Cav-3), myogenin and cardiac troponin I (cTrp). B: Example traces of cell contractions recorded in PML cells under control and after modulation with Epi, Ach, Ivabradine and E4031. C: Dose-response of contraction rate from PML cells under the condition in $C$ ( $n=7,11,9,6$ respectively). D: Example traces of APs recorded in PML cells under control and after modulation with Epi, ACh and TTX. E: Frequency change of spontaneous APs under the condition of A. Dashed line indicates AP rate in the control condition ( $n=9,8,6$ respectively). Paired Wilcoxon's t-tests between normalized internal control and values after drug perfusion. Two-way ANOVA/Dunnett's tests with multiple comparisons relative to the internal control. 

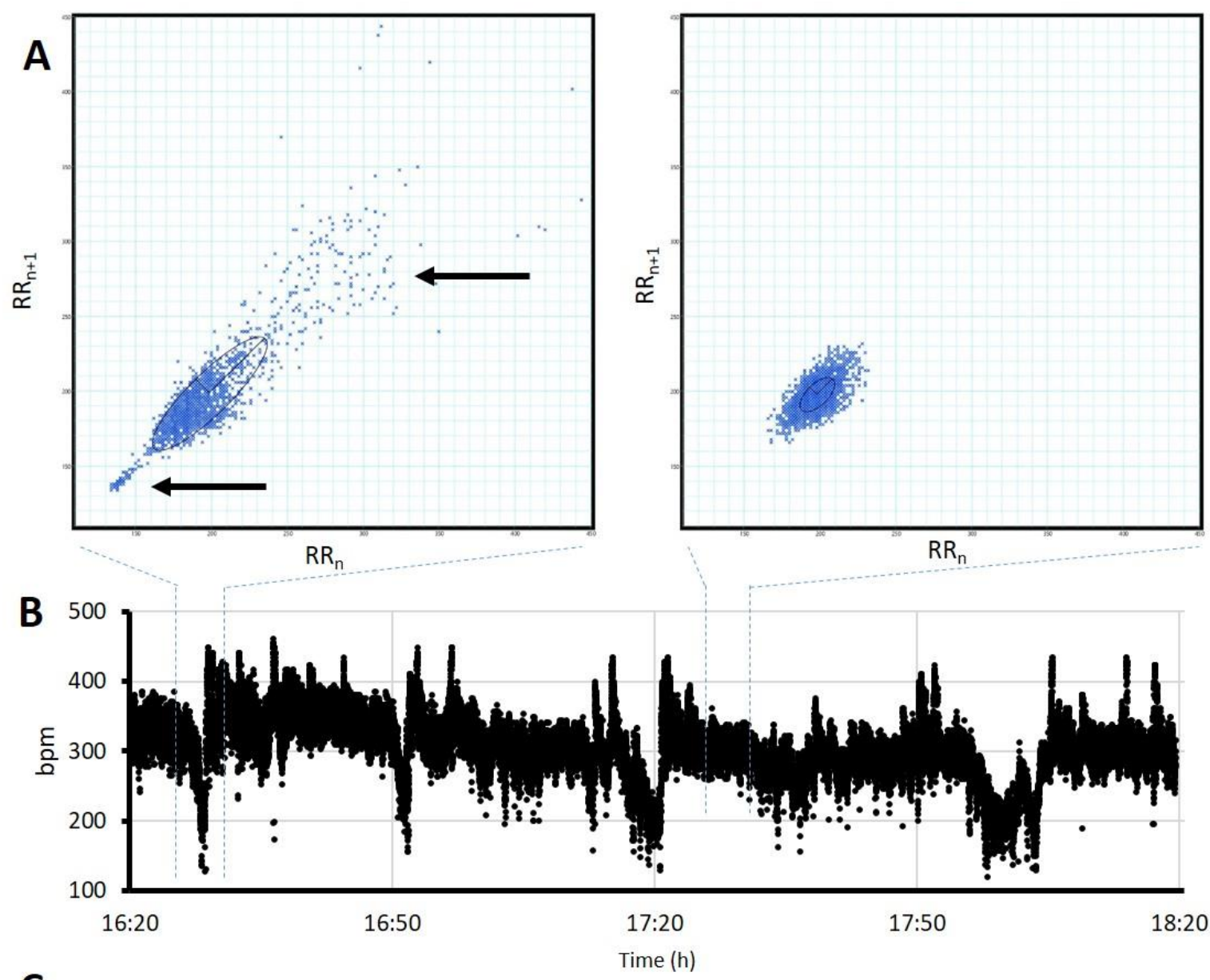

\section{C}

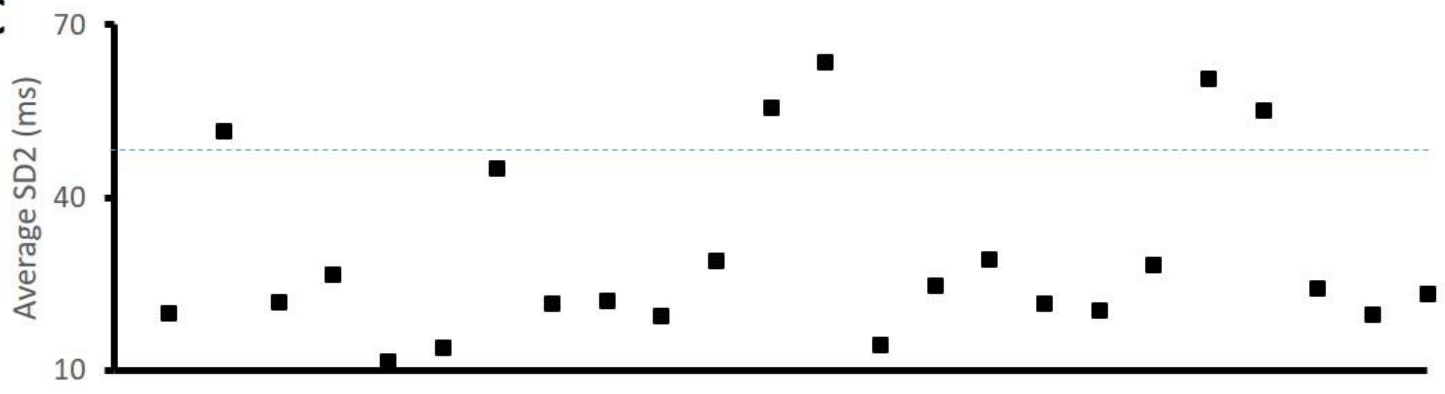

D

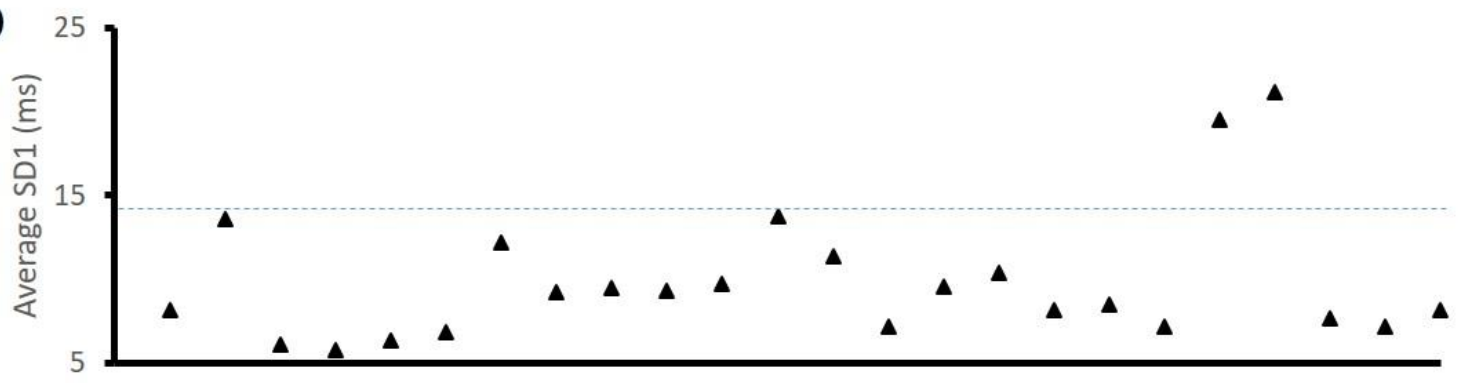

Suppl. Figure 1: Indexes of long- and short-term HRV in freely moving $M$. murinus.

A: Poincaré plots obtained analysing intervals of 5 min during high HRV and low HRV periods. Note in the left panel the presence of two clouds of points (arrows) separated from the main one and corresponding to fast and slow heart rate. B: Tachogram of HR versus time for a period of two hours. C and D: Plots obtained by measuring the average long- and short-term HRV (SD2 and SD1) of the Poincaré plot during intervals of 5 minutes corresponding to the tachogram in B. Dashed blue lines in $\mathrm{C}$ and $\mathrm{D}$ indicate the threshold of mean+SD of the reported parameters. 
A

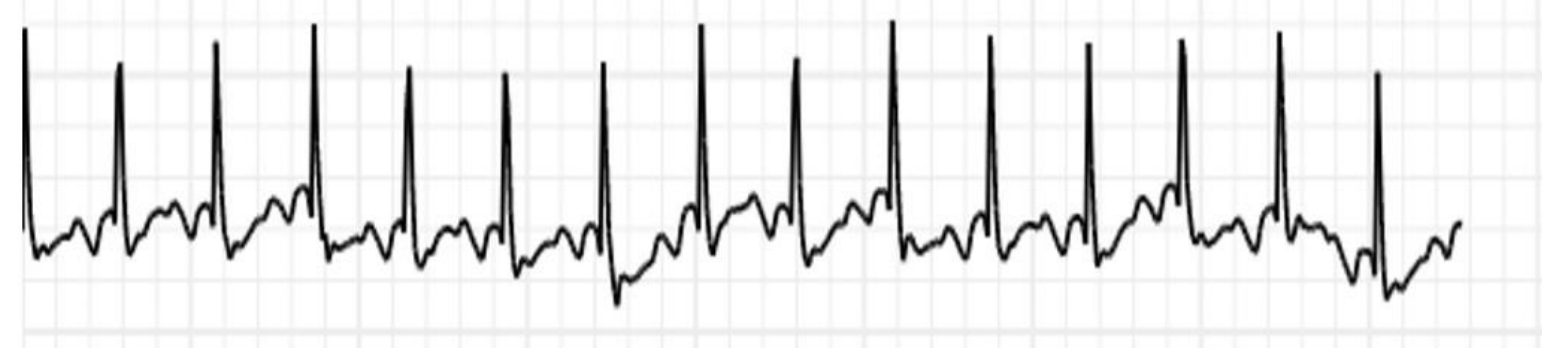

$0.2 \mathrm{~s}$

Suppl. Figure 2: Recordings of mouse lemur ECGs under manipulation, with Xiaomi Youpin HiPee Intelligent Dynamic Holter.

A: Example trace of ECG recorded in M. murinus 10 to 15 min after manipulation. 
A

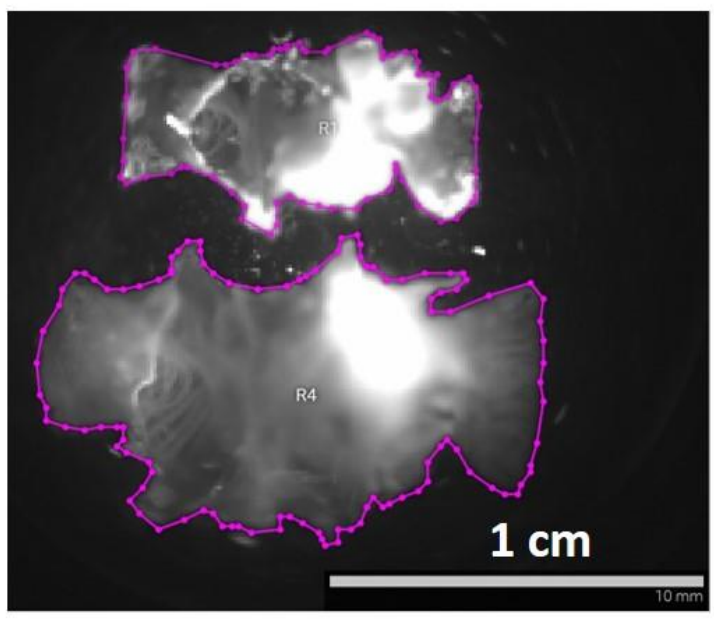

B

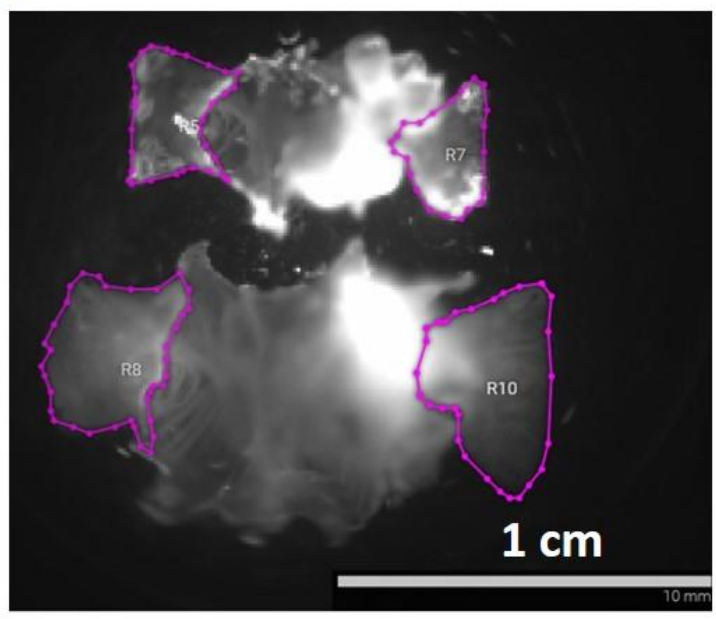

C

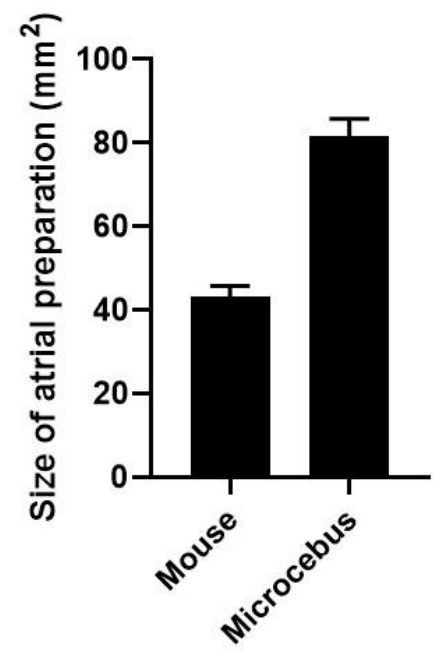

D

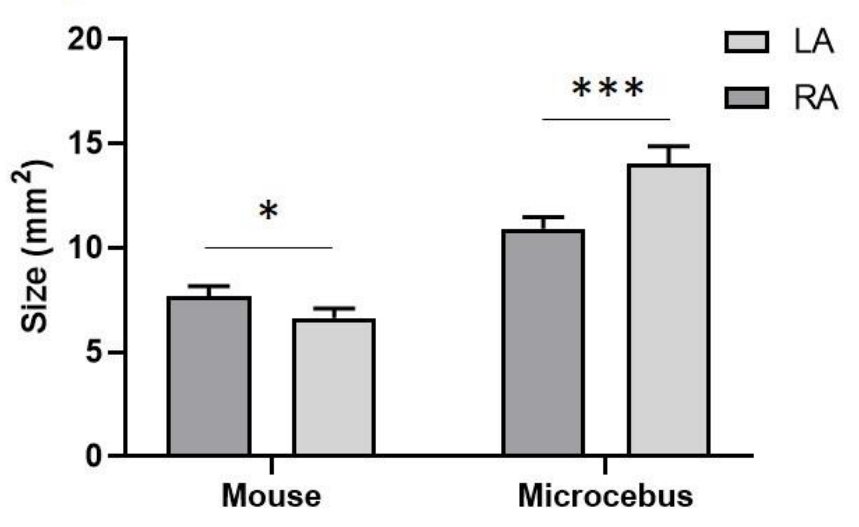

Suppl. Fig. 3: Size measurement of the atrial preparation of the heart.

A: Atrial preparation of $M$. murinus including SAN, RA and LA. Colour lines indicate the surface of the regions constituted by the whole atrial preparation (R1 and R4), the RA (R5 and R8) and the LA (R7 and R10). B: Size of the whole atrial preparation after dissection and removal of the ventricles. C: Size of right and left atria (RA and LA, respectively). $\mathrm{N}$ mice $=14$ and $\mathrm{n}$ Microcebus $=11$; One-way Anova with Sidak's multi-comparison test.

Suppl. Video 1: Dynamics of pacemaker generation and conduction within the atrial preparation of mice (up) and $\boldsymbol{M}$. murinus (down). Green to red colors indicated the intensity of depolarization in arbitrary units. 


\section{Bibliography}

1. Irisawa, H., Brown, H. F. \& Giles, W. Cardiac pacemaking in the sinoatrial node. Physiol. Rev. 73, 197-227 (1993).

2. Torrente, A. G. et al. L-type Cav1.3 channels regulate ryanodine receptor-dependent Ca2+ release during sino-atrial node pacemaker activity. Cardiovasc Res 109, 451-61 (2016).

3. Mangoni, M. E. \& Nargeot, J. Genesis and regulation of the heart automaticity. Physiol. Rev. $\mathbf{8 8}$, 919-82 (2008).

4. Ezran, C. et al. The Mouse Lemur, a Genetic Model Organism for Primate Biology, Behavior, and Health. Genetics 206, 651-664 (2017).

5. Dutrillaux, B. \& Rumpler, Y. Chromosome banding analogies between a prosimian (Microcebus murinus), a platyrrhine (Cebus capucinus), and man. Am J Phys Anthr. 52, 133-7 (1980).

6. Semelka, M., Gera, J. \& Usman, S. Sick sinus syndrome: a review. Am Fam Physician 87, 691-6 (2013).

7. Raatikainen, M. J. et al. Statistics on the use of cardiac electronic devices and electrophysiological procedures in the European Society of Cardiology countries: 2014 report from the European Heart Rhythm Association. Europace 17 Suppl 1, i1-75 (2015).

8. Swaminathan, P. D. et al. Oxidized CaMKII causes cardiac sinus node dysfunction in mice. J Clin Invest 121, 3277-88 (2011).

9. Jensen, P. N. et al. Incidence of and risk factors for sick sinus syndrome in the general population. J Am Coll Cardiol 64, 531-8 (2014).

10. Cingolani, E., Goldhaber, J. I. \& Marbán, E. Next-generation pacemakers: from small devices to biological pacemakers. Nat Rev Cardiol 15, 139-150 (2018).

11. Mesirca, P., Torrente, A. G. \& Mangoni, M. E. Functional role of voltage gated $\mathrm{Ca}(2+)$ channels in heart automaticity. Front Physiol 6, 19 (2015). 
12. Torrente, A. G., Mesirca, P., Bidaud, I. \& Mangoni, M. E. Channelopathies of voltage-gated L-type Cav1.3/a. Pflugers Arch 472, 817-830 (2020).

13. Peters, C. H., Sharpe, E. J. \& Proenza, C. Cardiac Pacemaker Activity and Aging. Annu Rev Physiol 82, 21-43 (2020).

14. Difrancesco, M. L., Mesirca, P., Bidaud, I., Isbrandt, D. \& Mangoni, M. E. The funny current in genetically modified mice. Prog. Biophys. Mol. Biol. S0079610721000638 (2021) doi:10.1016/j.pbiomolbio.2021.06.003.

15. Bychkov, R. et al. Synchronized Cardiac Impulses Emerge From Heterogeneous Local Calcium Signals Within and Among Cells of Pacemaker Tissue. JACC Clin Electrophysiol 6, 907-931 (2020).

16. Verkerk, A. O. et al. Pacemaker current $(I(f))$ in the human sinoatrial node. Eur. Heart J. 28, 2472-2478 (2007).

17. Baig, S. M. et al. Loss of $\mathrm{Ca}(\mathrm{v}) 1.3$ (CACNA1D) function in a human channelopathy with bradycardia and congenital deafness. Nat Neurosci 14, 77-84 (2011).

18. Neco, P. et al. Paradoxical effect of increased diastolic $\mathrm{Ca}(2+)$ release and decreased sinoatrial node activity in a mouse model of catecholaminergic polymorphic ventricular tachycardia. Circulation 126, 392-401 (2012).

19. Liang, D. et al. Cellular and molecular landscape of mammalian sinoatrial node revealed by single-cell RNA sequencing. Nat Commun 12, 287 (2021).

20. Alings, A. M., Abbas, R. F., de Jonge, B. \& Bouman, L. N. Structure and function of the simian sinoatrial node (Macaca fascicularis). J Mol Cell Cardiol 22, 1453-66 (1990).

21. Billman, G. E. et al. Selective vagal postganglionic innervation of the sinoatrial and atrioventricular nodes in the non-human primate. J Auton Nerv Syst 26, 27-36 (1989).

22. Fischer, K. E. \& Austad, S. N. The development of small primate models for aging research. ILAR J 52, 78-88 (2011). 
23. Bons, N., Rieger, F., Prudhomme, D., Fisher, A. \& Krause, K. H. Microcebus murinus: a useful primate model for human cerebral aging and Alzheimer's disease? Genes Brain Behav 5, 120-30 (2006).

24. Fritz, R. G. et al. Sex-specific patterns of age-related cerebral atrophy in a nonhuman primate Microcebus murinus. Neurobiol Aging 91, 148-159 (2020).

25. Schmidtke, D. et al. Linking cognition to age and amyloid- $\beta$ burden in the brain of a nonhuman primate (Microcebus murinus). Neurobiol Aging 94, 207-216 (2020).

26. Lasbleiz, C. et al. Combining Gene Transfer and Nonhuman Primates to Better Understand and Treat Parkinson's Disease. Front Mol Neurosci 12, 10 (2019).

27. Royo, J., Aujard, F. \& Pifferi, F. Daily Torpor and Sleep in a Non-human Primate, the Gray Mouse Lemur (\%B Front Neuroanat. 13, 87 (2019).

28. Zhang, J. et al. Regulation of Torpor in the Gray Mouse Lemur: Transcriptional and Translational Controls and Role of AMPK Signaling. Genomics Proteomics Bioinformatics 13, 103-10 (2015).

29. Arsic, N., Mamaeva, D., Lamb, N. J. \& Fernandez, A. Muscle-derived stem cells isolated as nonadherent population give rise to cardiac, skeletal muscle and neural lineages. Exp. Cell Res. 314, $1266-1280$ (2008).

30. Mesirca, P. et al. Bradycardic mice undergo effective heart rate improvement after specific homing to the sino-atrial node and differentiation of adult muscle derived stem cells. http://biorxiv.org/lookup/doi/10.1101/393512 (2018) doi:10.1101/393512.

31. Williams, T. M. \& Davis, R. W. Physiological resiliency in diving mammals: Insights on hypoxia protection using the Krogh principle to understand COVID-19 symptoms. Comp Biochem Physiol Mol Integr Physiol 253, 110849 (2021).

32. Fahlman, A. et al. Cardiorespiratory coupling in cetaceans; a physiological strategy to improve gas exchange? J Exp Biol 223, (2020). 
33. Mesirca, P. et al. The G-protein-gated K+ channel, IKACh, is required for regulation of pacemaker activity and recovery of resting heart rate after sympathetic stimulation. J Gen Physio/ 142, 11326 (2013).

34. McCraty, R. \& Shaffer, F. Heart Rate Variability: New Perspectives on Physiological Mechanisms, Assessment of Self-regulatory Capacity, and Health risk. Glob Adv Health Med 4, 46-61 (2015).

35. Pifferi, F., Epelbaum, J. \& Aujard, F. Strengths and Weaknesses of the Gray Mouse Lemur (\%B Front Pharmacol. 10, 1291 (2019).

36. Mertens, A., Stiedl, O., Steinlechner, S. \& Meyer, M. Cardiac dynamics during daily torpor in the Djungarian hamster (Phodopus sungorus). Am J Physiol Regul Integr Comp Physiol 294, R639-50 (2008).

37. Konopelski, P. \& Ufnal, M. Electrocardiography in rats: a comparison to human. Physiol Res 65, $717-725$ (2016).

38. Nerbonne, J. M., Nichols, C. G., Schwarz, T. L. \& Escande, D. Genetic manipulation of cardiac K(+) channel function in mice: what have we learned, and where do we go from here? Circ Res $\mathbf{8 9}$, 944-56 (2001).

39. Mesquita, T. R. R. et al. Mechanisms of atrial fibrillation in aged rats with heart failure with preserved ejection fraction. Heart Rhythm 17, 1025-1033 (2020).

40. Mesirca, P. et al. G protein-gated IKACh channels as therapeutic targets for treatment of sick sinus syndrome and heart block. Proc Natl Acad Sci U A 113, E932-41 (2016).

41. Baudot, M. et al. Concomitant genetic ablation of L-type Ca. Sci Rep 10, 18906 (2020).

42. Shinagawa, Y., Satoh, H. \& Noma, A. The sustained inward current and inward rectifier K+ current in pacemaker cells dissociated from rat sinoatrial node. J Physiol 523 Pt 3, 593-605 (2000).

43. Cho, H., Takano, M. \& Noma, A. The Electrophysiological Properties of Spontaneously Beating Pacemaker Cells Isolated from Mouse Sinoatrial Node. J. Physiol. 550, 169-180 (2003). 
44. Mangoni, M. E. \& Nargeot, J. Properties of the hyperpolarization-activated current $(I(f))$ in isolated mouse sino-atrial cells. Cardiovasc Res 52, 51-64 (2001).

45. Mangoni, M. E. et al. Functional role of L-type Cav1.3 Ca2+ channels in cardiac pacemaker activity. Proc. Natl. Acad. Sci. U. S. A. 100, 5543-8 (2003).

46. Mamaeva, D. et al. Novel roles for voltage-gated T-type $\mathrm{Ca}^{2+}$ and $\mathrm{ClC}-2$ channels in phagocytosis and angiogenic factor balance identified in human iPSC-derived RPE. FASEB J. 35, (2021).

47. Zohdy, S. et al. Teeth, sex, and testosterone: aging in the world's smallest primate. PloS One 9, e109528 (2014).

48. Steenman, M. \& Lande, G. Cardiac aging and heart disease in humans. Biophys. Rev. 9, 131-137 (2017).

49. Baudot, M. et al. Concomitant genetic ablation of L-type Ca. Sci Rep 10, 18906 (2020).

50. Lakatta, E. G., Maltsev, V. A. \& Vinogradova, T. M. A coupled SYSTEM of intracellular Ca2+ clocks and surface membrane voltage clocks controls the timekeeping mechanism of the heart's pacemaker. Circ. Res. 106, 659-73 (2010).

51. Hozer, C., Perret, M., Pavard, S. \& Pifferi, F. Survival is reduced when endogenous period deviates from $24 \mathrm{~h}$ in a non-human primate, supporting the circadian resonance theory. Sci. Rep. 10, $18002(2020)$.

52. Torrente, A. G. et al. Burst pacemaker activity of the sinoatrial node in sodium-calcium exchanger knockout mice. Proc Natl Acad Sci U A 112, 9769-74 (2015).

53. Mangoni, M. E., Marger, L. \& Nargeot, J. If current inhibition: cellular basis and physiology. Adv Cardiol 43, 17-30 (2006). 